CUADERNOS DE ESTUDIOS GALLEGOS, LVIII N. ${ }^{\circ} 124$, enero-diciembre (2011), pp. 149-182

ISSN 0210-847 X

\title{
LA CAPILLA DE LOS NEIRA DE LUACES EN LA IGLESIA COMPOSTELANA DE SANTA MARÍA DO CAMIÑO (SS. XVI-XIX)
}

RosaRio VALDÉs BLANCO-RAJOY Instituto de Estudios Gallegos "Padre Sarmiento"

CSIC-Xunta de Galicia 


\title{
LA CAPILLA DE LOS NEIRA DE LUACES EN LA IGLESIA COMPOSTELANA DE SANTA MARÍA DO CAMIÑO (SS. XVI-XIX) $)^{1}$
}

\begin{abstract}
RESUMEN
A partir de noticias epigráficas y documentales inéditas se puede establecer la fundación de la capilla de los Neira de Luces en la primera mitad del siglo XVI, bajo el patrocinio de Juan Outeiro regidor de la ciudad de Santiago. La capilla se encuentra en la iglesia compostelana de Santa María do Camiño, muy ligada a la tradición jacobea por estar situada en la entrada de la ciudad, junto a la antigua puerta del Camino Francés. Se sigue en lo posible su evolución hasta nuestros días, efectuando una labor de revisión y síntesis históriográfica que combina la evidencia material y la escrita. Se aportan además, algunos datos sobre determinados aspectos artísticos que adquieren nueva dimensión y significado al ser tratados en su conjunto, contextualizando el recinto funerario familiar en el ámbito urbano y considerando al mismo tiempo los diferentes períodos históricos.
\end{abstract}

PAlabras ClaVe: Santiago de Compostela. Camino Francés. Edad Moderna. Edad Contemporánea. Sociedad. Capellanías. Mecenazgo. Arquitectura. Escultura. Pintura. Heráldica.

\section{THE NEIRA DE LUACES CHAPEL IN SANTA MARÍA DO CAMIÑO $\left(16^{\text {th }}-19^{\text {th }}\right)$. SANTIAGO DE COMPOSTELA}

\begin{abstract}
Using epigraphic testimonies and unpublished documents, we can establish that the chapel of the family Neira de Luaces was founded in the first quarter of the 16th Century, being sponsored by Juan Outeiro, ancient alderman of Santiago de Compostela. This chapel is in the church of Santa María do Camiño, a building directly linked with the pilgrimages tradition, situated near of the old door of the French Way. We try to describe the historical evolution of this chapel till today, making a bibliographical review and a historiographical synthesis, where are combined material evidences and textual testimonies. We are also publishing new information about its artistic configuration that acquires a new dimension and a new meaning, being understood in the context of the family pantheon.
\end{abstract}

KEY WORDS: Santiago de Compostela, French Way, Modern Age, Contemporary Age, Society, Chaplaincy, Patronage, Architecture, Sculpture, Painting, Heraldry.

\footnotetext{
${ }^{1}$ Este artículo se ha realizado dentro del proyecto de investigación "Diccionario Histórico dos Camiños de Santiago en Galicia" (Código: PGIDIT07PXIB606078PR), que se viene desarrollando en el Instituto de Estudios Gallegos "Padre Sarmiento" (CSIC-XUGA).
} 
Recibido/Received: 04/07/2011

Aceptado/Accepted: 27/07/2011

\section{LA iglesia compostelana de SANTA María do CAMiÑo y El ENTORNO URBANO.}

$\mathrm{L}$

A llamada "Porta do Camiño" de la ciudad de Santiago de Compostela, corresponde a la antigua "porta Francigena" que menciona el Códice Calixtino como "primus introitus" de la urbe ${ }^{2}$. No solo era la entrada correspondiente al Camino Francés por tanto, una de las más transitadas de la ciudad, sino también el nexo de unión entre la ciudad amurallada y el antiguo arrabal de San Pedro, el primero y quizá el más populoso de Compostela que se habría creado en el siglo X, en la márgenes del propio camino, extramuros y en el entorno del antiguo monasterio de "San Pedro de Afora"3. La fábrica medieval de este monasterio era de estilo románico, muy semejante a la de Santa María del Sar; fue definitivamente demolida en 1839. En su lugar se levanta hoy en día el edificio neoclasicista de la iglesia parroquial de San Pedro ${ }^{4}$.

En el mismo arrabal de San Pedro se encuentra la capilla de "Nosa Señora da Quinta Angustia" o de la "Angustia de Arriba", erigida por Cristóval Francés en 1465, quien en esa fecha recibió de manos del abad de San Pedro de Afora, el foro

\footnotetext{
${ }^{2}$ LÓPEZ PEREIRA, Eduardo (Est., ed. y trad.), Guía medieval do peregrino. Códice Calixtino, libro V. Vigo, 1993, pp. 186 y 189.

${ }^{3}$ LÓPEZ ALSINA, Fernando, La ciudad de Santiago de Compostela en la alta Edad Media. Santiago de Compostela, 1988, pp. 145, 254 y 275.

${ }^{4}$ BARREIRO VÁZQUEZ VARELA, Bernardo, Guía histórica, artística, arqueológica y militar de la antigua capital de Galicia, Santiago de Compostela. Santiago, 1886, $\mathrm{n}^{\circ} 61$ del texto adjunto al mapa. VÁZQUEZ DE PARGA, Luis - LACARRA, José María - URÍA RIU, Juan, Las peregrinaciones a Santiago de Compostela, tomo 2. Madrid, 1948, pp. 393-395. CASTRO VÁZQUEZ, Josefina, El Camino de Santiago (entre Portomarín y Compostela). Lugo. 1991, p. 70. YZQUIERDO PERRÍN, Ramón, "Os templos parroquiais. San Pedro", Santiago de Compostela. Patrimonio Histórico Gallego I. Ciudades, vol. 2. Xosé Manuel García Iglesias (Dir.). Laracha (A Coruña), 1993, p. 227. YZQUIERDO PERRÍN, Ramón, "Arte Medieval (I)", Galicia. Arte, tomo 10. Francisco Rodríguez Iglesias (Dir.). A Coruña, 1995, p. 267. YZQUIERDO PERRÍN, Ramón, “Arte Medieval (II)”, Galicia. Arte, tomo 11. Francisco Rodríguez Iglesias (Dir.) A Coruña,1995, pp. 129-130.
} 
de un solar para poder edificarla ${ }^{5}$; en la inscripción fundacional (que se conserva en el dintel de la puerta de la sacristía), se menciona la ermita junto con un hospital ${ }^{6}$. Precisamente en "unos hospitales" que estaban cerca de esta capilla, fue donde se recluyó a los afectados por el brote de peste que se produjo en la ciudad en $1597^{7}$. El visitador Jerónimo del Hoyo indica que lo que allí había por entonces eran " [... ] tres casas junto a Nuestra Señora de la Angustia para los pobres de mal contagios, a cargo de los limosneros que fuesen de los señores arçobispos [...]"8.

Más cerca de la Puerta del Camino se levantó el convento de "San Domingos de Bonabal", cuya primera iglesia se consagró en el año 1230. Fueron muchos los clérigos de la ciudad y también miembros de la nobleza y de la burguesía más acomodada, los que se enterraron tanto en el interior de la iglesia como en los claustros; destacan los cuatro sepulcros de la capilla mayor que ostentan las armas de los Moscoso, los Do Campo y los Andrade, realizados en el primer cuarto del siglo XV, cuando Constanza de Moscoso fundó el patronato de dicha capilla y comenzó con ello, el mecenazgo de esa familia a favor del convento ${ }^{9}$.

El Camino Francés se denominó más tardiamente como Camino de Castilla y a su paso por el arrabal compostelano, llevaba el nombre preciso de "Rúa de San Pedro" con que se conoce hoy en día. A mediados del siglo XVI las rúas de San Pedro y Hortas eran las dos calles principales de la ciudad por el tráfico de personas y mercancías; según varios testimonios de la época, ninguna de ellas

\footnotetext{
5 VILLAMIL Y CASTRO, José, Reseña histórica de los establecimientos de beneficiencia que hubo en Galicia durante la Edad Media, y de la erección del Gran Hospital Real de Santiago fundado por los Reyes Católicos y constituciones del Gran Hospital Real de Santiago de Galicia, hechas por el Señor Emperador Carlos Quinto de Gloriosa Memoria. Año de 1524. Consorcio da Cidade de Santiago de Compostela - Universidad de Santiago de Compostela - Cátedra de Medicina Preventiva y Salud Pública, (Eds.). Santiago de Compostela, (D.L. 1993), p. 92. VÁZQUEZ DE PARGA, Luis - LACARRA, José María - URÍA RIU, Juan, Las peregrinaciones, tomo 2, p. 394. 6 YZQUIERDO PERRÍN, Ramón, "Dos capillas compostelanas dedicadas a la Virgen de las Angustias". Actas de la III Semana Mariana en Compostela. Santiago, 13-18 de octubre de 1997. (Santiago, 1998), pp. 62-63. YZQUIERDO PERRÍN, Ramón, Santiago de Compostela en la Edad Media. Madrid, 2002, p. 115.

7 BARREIRO MALLÓN, Baudilio - REY CASTELAO, Ofelia, Pobres, peregrinos y enfermos: la red asistencial gallega en el Antiguo Régimen. Vigo, [1999], p. 183.

${ }^{8}$ HOYO Jerónimo del, Memoria de las iglesias del arzobispado de Santiago quien presenta para ellas y de las feligreses que cada una tiene de su valor y de las sincuras repartidas por las desta ciudad de Santiago y el deanazgo y arcedianatos de Nendos y Cornado, Trastámara y Salnés con las de Cacabelos, León y Castilla y las vicarias de Alba y Aliste, Carbajales y Alcaniças dispuesto por D. Jerónimo del Hoyo, Canónigo y Cardenal de esta Santa Iglesia y Visitador del Arzobispado por el Sr. Maximiliano de Austria, año 1607. Ángel Rodríguez González - Benito Varela Jácome (Eds. y trans. del ms. original). Santiago de Compostela, s/a, p. 130.

9 FOLGAR DE LA CALLE, María del Carmen, "Os conventos. Dominicos. Convento de San Domingos de Bonaval", Santiago de Compostela. Patrimonio Histórico Gallego I. Ciudades, vol. 2. Xosé Manuel García Iglesias (Dir.). Laracha (A Coruña), 1993, pp. 356-371.
} 
estaba empedrada por lo que "[...] las dichas calles ban muy fondidas e las casas quedan muy altas e descobiertos los cimientos y en muchas partes ha menester para subir a ellas dos o tres grades y están muy peligrosas para se caer [...]" y en el invierno el agua de la lluvia, traía "[...] muchos lodos y fosas de tal manera que no pueden por ellas andar ni caminar a pie ni a caballos sino con trabaxo [... ]", todo ello iba en detrimento de los vecinos, moradores "[...] e peligrinos e romeros y caminantes [...]"10.

La Rúa de San Pedro desembocaba ante la Puerta del Camino, donde se efectuaba el ceremonial de recibimiento y entrega de las llaves a los arzobispos compostelanos -señores de la ciudad-, cuyos blasones se pintaban sobre el arco de la entrada $^{11}$. En el año 1670 Domenico Laffi clerigo boloñés, que visita por segunda vez la ciudad compostelana dice que esa puerta era toda de mampostería; tenía una fuente junto a ella y un puente delante. El puente cruzaba un pequeño riachuelo que discurría contra la muralla de la ciudad por la parte de oriente ${ }^{12}$; en sus márgenes, entre las puertas del "Camiño" y la de "Mámoa", estaban establecidas una serie de curtidurías cuyas ordenanzas habían sido aceptadas por el concejo en el año 1503. En ese negocio tenía parte la iglesia de Santa María ${ }^{13}$, que se encontraba junto a la misma puerta dentro ya de la ciudad, a mano izquierda de la llamada "rúa do Camiño" que conducía directamente hacia la catedral ${ }^{14}$ (fig. 1).

La primera noticia que se refiere a esta iglesia de Santa María do Camiño, la encontramos en el testamento del cardenal de Santiago Lorenzo Domínguez, fechado en el año 1276, donde se menciona junto a otras iglesias y ermitas de la ciudad de Santiago que reciben una manda del cardenal: “ [...] Ecclesiis sce. Trinitatis et sci. Pauli de pedre. sci. Laurentii de trasaltu. Sce Susane. Sce. Marine de Heremita sce. Marie de Rua noua. Sci. Benedictii. Sci. Michaelis de cisterna et sce. Marie de Rua de Camino binos sls. [...]". De igual manera, "sta. Maria do camio" vuelve a recibir un legado en el año 1348, que le deja en su testamento María López, vecina de Compostela ${ }^{15}$.

10 RODRÍGUEZ GONZÁLEZ, Ángel, "La ciudad de Santiago en 1542”. Cuadernos de Estudios Gallegos, tomo 25. (Santiago de Compostela, 1970), pp. 273-275.

11 BARREIRO VÁZQUEZ VARELA, Bernardo, Guía histórica, no 59 del texto adjunto al mapa. De cómo era dicho ceremonial a principios del siglo XVII, nos queda descripción detallada en la documentación; GOY DIZ, Ana, A actividade artística en Santiago, 1600-1648, vol. 2. Santiago de Compostela, 2007, docs. DCXLI y DCLXVI, pp. 331 y 338-339.

12 LAFFI, Dómenico, Viaggio in Ponente a San Giacomo di Galitia e Finisterrae. Anna Sulai Capponi (Ed. y notas). Perugia, 1989, p. 201.

13 GELABERT GONZÁLEZ, Juan Eloy, Santiago y la tierra de Santiago de 1500 a 1640. A Coruña, 1982, p. 239.

${ }^{14}$ HOYO, Jerónimo del, Memoria, p. 87.

15 LÓPEZ FERREIRO, Antonio, Colección diplomática de Galicia histórica. Santiago de Compostela, 1901, docs. XLVI y XXXII, pp. 220 y 149. 


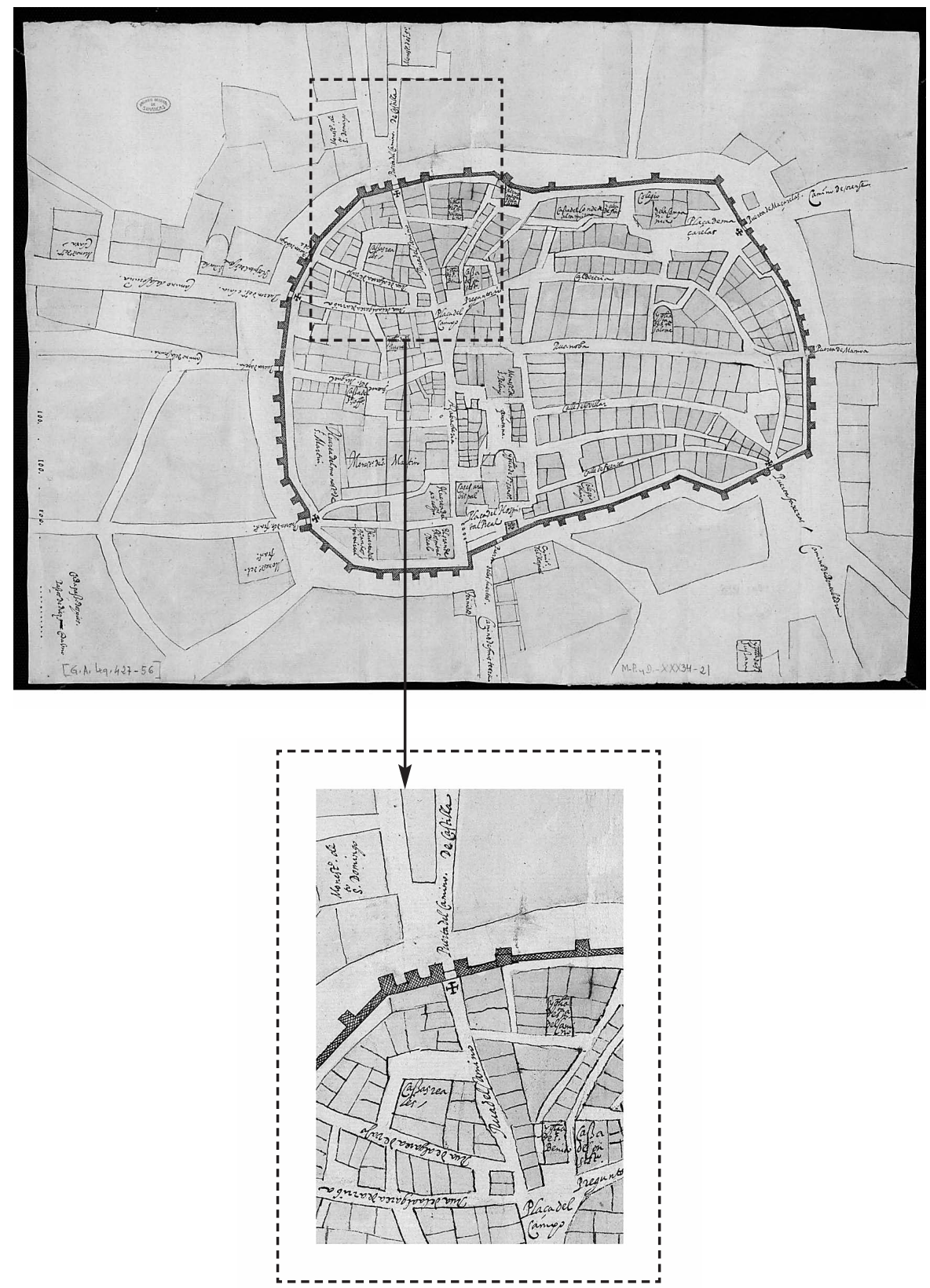

Fig. 1

Plano de la ciudad de Santiago de Compostela del año 1595. España. Ministerio de Cultura. Archivo General de Simancas, MPD, 34, 21 
Muy próximo a la iglesia de Santa María estaba el hospital para peregrinos de San Miguel fundado por el canónigo de Santiago, Ruy Sánchez de Moscoso quien dejó para ello su "[...] cassa de morada na dita Rua do Camiño destas portas adentro [...]", tal como se dice en su testamento abierto en el año 1400, el establecimiento reunía un mesón que debería llamarse del "Santo Spirito" y un hospital "nomeado de Santa María". Además de las salas destinadas para dormitorio y servicio de los acogidos, había una huerta en la parte de atrás, una capilla dedicada a San Miguel y una biblioteca con libros de oraciones, de teología, filosofía, derecho canónigo, medicina y física. Posteriormente este hospital sirvió también, para acoger a "[...] pobres y enfermos, naturales del reino [...]"; en 1760, fue anexionado al hospital de San Roque, sito en la misma ciudad de Santiago, próximo a la "Porta da Pena"16.

En las últimas décadas del siglo XIX, todavía recordaba Bernardo Barreiro la casa que ocupaba el solar del antiguo hospital en la "rúa do Camiño", que aunque había sido reedificada en el siglo XVIII, conservaba "[...] sus escudos de armas de los Moscosos, cinco cabezas de lobo, abiertas las fauces y sacando largas lenguas; formando un rinconcillo al lado de las antiguas casas de la Real Audiencia de Galicia, sin ventanas, las puertas desvencijadas y como bienes de menores [... ]". Barreiro dice también que "[...] el antiguo edificio construído a la muerte del fundador Ruy Sánchez de Moscoso, como del siglo XV, era una casa-capilla de estilo ojival, según consta en varios documentos, con una torre y sus campanas y sobre el pórtico una hornacina con la imagen de San Miguel [...]"17.

En efecto, como señala Bernardo Barreiro, en la misma calle -un poco más arriba del hospital de San Miguel- se encontraban las casas que desde comienzos del siglo XVI, albergaron la sede la Real Audiencia de Galicia junto con sus cárceles ${ }^{18}$. La sede ocupaba además de la llamada casa principal, otras casas accesorias que le eran colindantes, lo que dio lugar a que partir de entonces y hasta hoy, el tramo de la calle en que se ubicaba la Real Audiencia se conociese como "rúa das Casas Reais". A juzgar por el plano que de estos inmuebles levantó Juan López Freire entre los años 1782 y 1783, la casa principal era una residencia de

16 VILLAMIL Y CASTRO, José, Reseña, pp. 93-96. Una transcripción completa del testamento
está publicada en: RODRÍGUEZ GONZÁLEZ, Ángel, "El hospital de San Miguel del Camino para
pobres y peregrinos (siglos XV al XVIII)". Compostellanum, vol. 12, nº 2 (Santiago de Compostela,
1967), Apéndices, pp. 225-232. BARREIRO MALLÓN, Baudilio - REY CASTELAO, Ofelia, Po-
bres, p. 62. OTERO TÚNEZ, Ramón, "Santa María del Camino". Actas de la II Semana Mariana
en Compostela. Santiago, 1-6 de octubre de 1996. (Santiago, 1997), p. 110 .
17 BARREIRO VÁZQUEZ VARELA, Bernardo, "Dos palabras sobre el testamento inédito de Ruy
Sánchez de Moscoso". Galicia Diplomática, año 3, no 45 (1888), p. 325-327; cit en: RODRÍGUEZ
GONZÁLEZ, Ángel, "El hospital de San Miguel", p. 203 .
18 BARREIRO, VÁZQUEZ VARELA, Bernardo, Guía histórica, nº 52 del texto adjunto al mapa. 
carácter señorial con capilla propia, cuyas dependencias se distribuían y organizaban en torno a un patio porticado, con tres arcos abiertos en cada uno de sus cuatro lados ${ }^{19}$; la construcción puede adscribirse -cuando menos- al final de la Edad Media, comienzos de la Edad Moderna ${ }^{20}$.

López y López dice que en la misma manzana de la calle, estuvo también la casa del Dr. Beltrán abogado del Concejo, en donde se hospedó Felipe el Hermoso con su esposa Juana en 1506, cuando vinieron de Flandes para posesionarse del trono de Castilla ${ }^{21}$.

Al otro lado de la "rúa do Camiño", enfrente del lugar donde estuvo la Real Audiencia, se conserva -todavía hoy- otra casa-palacio en la que destaca la portada principal con un arco conopial de amplio dovelaje. En su fachada se colocaron varios escudos que ostentan -entre otras- las armas de los Luaces; esta casa la tuvo Bernardo de Luaces, que a mediados del siglo XVI había creado uno de los mayorazgos más importantes de Santiago con " [...] las casas de este Mayorazgo frontero de las casas reales de dicha ciudad $[\ldots]^{22}$.

En 1545 la Real Audiencia se traslada a la ciudad de A Coruña y casi un siglo después, concretamente en 1641, las casas de su antigua sede son cedidas a María Cores para que estableciese el "Hospital y Seminario de Pobres Impedidos y Niñas Desamparadas"; la intención primera de esta última institución fue la de se recluyesen en ella a las mujeres de "mal vivir". En 1730 se le incorporó la acogida de los tullidos hasta el punto de que en 1771, sus bienes y la propia fundación pasaron a engrosar los fondos de la "Casa de Pobres Tullidos Recogidos y Niñas Desamparadas" establecida en el nuevo asilo del barrio de Tarás, conocido como Asilo de Carretas, que fue fundado por el arzobispo Rajoy. La anexión significó el abandono de su antiguo emplazamiento ${ }^{23}$. En el tiempo en que funcionó el hospital, se

19 En el interior de la casa que actualmente lleva el número 14 de la calle de la Algalia de Abaixo, todavía se conservan tres de estos arcos de medio punto, apoyados sobre columnas y capiteles ricamente decorados con motivos figurados que componen escenas de lucha entre animales y también de caza o cetrería; pueden verse además, algunos arcos conopiales correspondientes a distintas puertas y ventanas; véase: GONZÁLEZ LÓPEZ, Miguel Ángel, "La intervención arqueológica en la sede de la Real Audiencia del reino de Galicia. Rúa de la Algalia de Abaixo. Santiago de Compostela". Del documento escrito a la evidencia material. Actas del Primer Encuentro Compostelano de Arqueología Medieval. Mercedes López-Mayán Navarrete - Carlos J. Galbán Malagón (Coords.). Santiago de Compostela, 2007, pp. 313-330.

${ }^{20}$ SINGUl LORENZO, Francisco, Santa María del Camino, Ánimas y San Benito del Campo. Santiago de Compostela. Santiago de Compostela, (D.L. 2000), p. 65.

${ }^{21}$ LÓPEZ Y LÓPEZ, Román, Santiago de Compostela, Guía del peregrino y del turista. Santiago, 1928 , p. 158.

22 BOUZA-BREY TRILLO, Fermín, "El origen y descendencia de los Luaces. Manuscrito del Siglo XVII". Boletín de la Comisión Provincial de Monumentos Histórico-Artísticos de Orense, tomo 17, fasc. 3, ( Ourense, 1951), p. 233.

${ }^{23}$ BARREIRO MALLÓN, Baudilio - REY CASTELAO, Ofelia., Pobres, pp. 59 y 111-112. 
fueron vendiendo varios de los inmuebles de la plazuela y del callejón de las "Casas Reais". Precisamente fueron los descendientes de una rama familiar de los Luaces (que por entonces ostentaban los títulos de señores de Oca y condes de Amarante), los que compraron al menos tres de estas casas, cuyo dominio era de "las Niñas Desamparadas", a las que pagaban por ello rentas y pensiones ${ }^{24}$.

Tras el traslado del Hospital de las Desamparadas, la Cofradía General de Ánimas compró el solar para levartar en él su propia capilla, lo que supuso el derribo de gran parte de las antiguas edificaciones. La capilla de las Ánimas -que es la construcción que hoy nos resta- se empezó a levantar en el año 1784, bajo la dirección del maestro de obras Juan López Freire. El nuevo templo se bendijo en el año $1788^{25}$.

Dejando atrás las "Casas Reais" y antes de llegar a la catedral, se cruzaba la plaza del Campo (hoy de Cervantes), antiguo mercado y centro neurálgico donde a comienzos del siglo XVII se desarrollaban los principales eventos de la ciudad como podían ser el levantamiento de pendones por el rey, las celebraciones por la "buena venida" de los arzobispos y también otros actos de carácter festivo como eran "los toros", "las máscaras" y las carreras de "la sortija", que se sucedían a lo largo de una semana con motivo de la onomástica del Apóstol Santiago ${ }^{26}$. En la organización de todo ello participaban activamente los regidores de la ciudad y otras autoridades locales, que además contribuían a sufragar los costos.

En la plaza del Campo se encuentra todavía hoy la iglesia de San Benito, que se levantó en el solar de otra fábrica construida en tiempos del obispo Pelayo Rodríguez (muerto en el año 985); era la octaba de las diez iglesias que según el Códice Calixtino había en la ciudad de Santiago. Reconstruida por el arzobispo Gelmírez en 1122, volvió a ser reedificada en el siglo XVIII ${ }^{27}$. Junto a la iglesia

${ }^{24}$ CRESPO DEL POZO, José Santiago, Blasones y Linajes de Galicia, vol. 4. Bilbao, [1983], p. 9.

25 LÓPEZ VÁZQUEZ, Xosé Manuel, "A Arquitectura Neoclásica". Galicia Arte, tomo 15. Francisco Rodríguez Iglesias (Dir.). A Coruña, 1995, p. 64. LÓPEZ VÁZQUEZ, Xosé Manuel, "Xeral de Ánimas", Santiago de Compostela. Patrimonio Histórico Gallego I. Ciudades, vol. 2. Xosé Manuel García Iglesias (Dir.). Laracha (A Coruña), 1993, pp. 190-194. SORALUCE BLOND, José Ramón - FERNÁNDEZ FERNÁNDEZ, Xosé, Arquitecturas da provincia da Coruña. Santiago de Compostela, vol. 11. (D.L. 1997), pp. 206-207. SINGUL LORENZO, Francisco, Santa María del Camino, pp. 39-41.

${ }^{26}$ GOY DIZ, Ana, A actividade, vol. 2, docs. CDLVI y DCXCVIII, pp. 279 y 350.

${ }^{27}$ LÓPEZ ALSINA, Fernando, La ciudad, p. 258. MORALEJO LASO, Abelardo - TORRES, Casimiro - FEO GARCÍA, Julio (Trads.), Liber Sancti Jacobi “Codex Calixtinus”. Pontevedra, (D.L. 1992), p. 552. FALQUE REY, Emma (Intro., trad., notas e índ.), Historia Compostelana. Madrid, 1994, p. 402. LÓPEZ Y LÓPEZ, Román, Santiago de Compostela, p. 157. FILGUEIRA VALVERDE, José, Santiago de Compostela. Guía de sus monumentos e itinerarios. La Coruña, 1950, p. 111. CASTILLO LÓPEZ, Ángel del, Inventario de la riqueza monumental y artística de Galicia. Santiago de Compostela, 1987, p. 553. SORALUCE BLOND, José Ramón - FERNÁNDEZ FERNÁNDEZ, Xosé., Arquitecturas, p. 208. 
de San Benito, por el lado del mediodía, se encontraban las antiguas casas del cabildo y al otro lado se alzaba una casa construida en estilo gótico ojival, de la que fue dueña Urraca de Moscoso a finales del siglo XV ${ }^{28}$.

Además de estos inmuebles había en la misma plaza, una fuente que a mediados del siglo XVI ya estaba muy necesitada de reparaciones y hacía tiempo que no recibía agua, a pesar de ser "[...] la fuente mas principal que está el mas en medio de la dicha çiudad [de Santiago] e conbersación de los veçinos della y de que todos gozan e para todos los romeros que bienen a este glorioso Apóstol Señor Santiago [...]"; se consideraba la más necesaria para el servicio de la ciudad y " $[\ldots]$ para remedio de fuegos quando subçeden [...]"29. A finales del mismo siglo, la fuente continuaba en muy mal estado (lo mismo que la fuente de la Puerta del Camino), por lo que en el año de 1600 el cabildo mandó pagar las correspondientes reparaciones a cuenta del portazgo de la ciudad ${ }^{30}$.

Volviendo de nuevo a la iglesia de Santa María do Camiño, nos queda por decir que, al igual que la iglesia de San Benito, fue reedificada en la segunda mitad el siglo XVIII; entre los años 1747 y 1749 se demolió y se fabricó de nuevo la capilla mayor, dándole más anchura de la que tenía. Pocos años más tarde, sobre el año 1770 se rehizo la nave y la fachada principal de la iglesia, siguiendo el proyecto trazado por el arquitecto Ferro Caaveiro ${ }^{31}$.

Según Otero Túñez, la fábrica medieval de la iglesia constaba de una sola nave de planta rectangular de la misma anchura que la actual, estaría flanqueada de sepulcros y tendría la techumbre de madera. La capilla mayor sería igualmente de planta rectangular, pero más estrecha que la nave y estaría presidida por la imagen de la Virgen María. De esta primitiva edificación restan dos cruces de consagración que se localizan a cada lado del tramo de acceso a la iglesia y otras

${ }^{28}$ LÓPEZ FERREIRO, Antonio, (Ed.), "Testamento de D ${ }^{\mathrm{a}}$ Urraca de Moscoso, madre del segundo Conde de Altamira D. Rodrigo Osorio de Moscoso (...)", Colección Diplomática de Galicia Histórica, tomo 1. Santiago de Compostela, 1901, doc. C, pp. 438 y ss. BARREIRO VÁZZUEZ VARELA, Bernardo, Guía histórica, $\mathrm{n}^{\circ} 51$ del texto adjunto al mapa. GELABERT GONZÁLEZ, Juan Eloy, Santiago, pp. 189-190, (fotografía 5, entre pp. 192 y 193).

${ }^{29}$ RODRÍGUEZ GONZÁLEZ, Ángel, "La ciudad”, pp. 276-277.

${ }^{30}$ GOY DIZ, Ana, A actividade, vol. 2, doc. CCCLXXXV, p. 257.

${ }^{31}$ COUSELO BOUZAS, José, Galicia artística en el siglo XVIII y primer tercio del siglo XIX. Anexo 34 de Cuadernos de Estudios Gallegos; Santiago de Compostela, 2005, pp. 415-416. GARCÍA-ALCAÑIZ YUSTE, Julia, Arquitectura del neoclásico en Galicia. A Coruña, 1989, p. 189. LÓPEZ VÁZQUEZ, Xosé Manuel, "Santa María do Camiño", Santiago de Compostela. Patrimonio Histórico Gallego I. Ciudades, vol. 2. Xosé Manuel García Iglesias (Dir.). Laracha (A Coruña), 1993, pp. 189-191. GARCÍA IGLESIAS, Xosé Manuel, "O Barroco (II)". Galicia Arte, tomo 14. Francisco Rodríguez Iglesias (Dir.). A Coruña, 1995, p. 119. LÓPEZ VÁZQUEZ, Xosé Manuel, "A Arquitectura Neoclásica", p. 63. SORALUCE BLOND, José Ramón - FERNÁNDEZ FERNÁNDEZ, Xosé, Arquitecturas, pp. 204-205. OTERO TÚÑEZ, Ramón, "Santa María del Camino", pp. 119-137. SINGUL LORENZO, Francisco, Santa María del Camino, pp. 11-15. 
varias formando parte de de los muros exteriores. Se conserva además el tímpano de la portada principal donde se representa el tema de la adoración de los Reyes Magos; esta pieza -que se guarda dentro de la iglesia- está fechada por la inscripción que tiene en el dintel, en el año $1425^{32}$.

También en el interior del templo, empotrado en el muro norte de la nave y oculto trás la estructura del confesionario que antecede al retablo de la Aurora (antes de San Gabriel), se encuentra un arco ligeramente apuntado y de gruesos bocelones, que debió cobijar el sepulcro del fundador del hospital de San Miguel, Ruy Sánchez de Moscoso; en su testamento consta que dicho sepulcro estaba "[...] dentro en na capella de santa María do Camino a os pes da sepultura do meu aboo, Juan Bidal do Camino, çibdadao de Santiago a quen deus perdon en na outra sepultura conjunta co a sua cerca do altar de San Gabriel arcangeo que hesta fora das gradecelas do altar maior da dita capella as quaes sepulturas ambas scriptas e labradas y estremadas hestan dentro en dous arcos como por ellas pareçe [...]"33. Jerónimo del Hoyo describe estas mismas sepulturas de la siguiente manera: "[...] Al lado del Ebangelio desta dicha capilla [de Santa María do Camiño], antes de entrar en la capilla mayor, hay dos arcos con dos entierros. Dicen son del que fundó y dotó el hospital de San Miguel, que en el de más arriba está el dicho fundador y en el otro sus padres [...]"34.

Estos sepulcros de los Moscoso quizá se integrasen en el contexto fundacional de una capellanía familiar, dado que Urraca de Moscoso en su testamento, fechado en el año 1498, dejo una partida “[...] para alumbrar la lámpara en la capilla de sta. maria del camino desta dicha cibdad [de Santiago]" y encarga que el día de su entierro le digan misas, además de otros frailes y clérigos de Compostela, "[...] el mi capellan de sta. maria del camino [...]"35. Sea como fuere, los sepulcros han desaparecido, habiendo en la pared del arcosolio que se conserva,

32 BARREIRO VÁZQUEZ VARELA, Bernardo, Guía histórica, nº 56 del texto adjunto al mapa. LÓPEZ Y LÓPEZ, Román, Santiago de Compostela, p. 158. FILGUEIRA VALVERDE, José, Santiago de Compostela, pp. 108-109. CASTILLO LÓPEZ, Ángel del, Inventario, p. 553. SORALUCE BLOND, José Ramón - FERNÁNDEZ FERNÁNDEZ, Xosé, Arquitecturas, p. 159. OTERO TÚÑEZ, Ramón, "Santa María del Camino", pp. 108-111. Por lo que se refiere a la advocación que preside el culto de esta iglesia, apunta Cendón Fernández que en el vértice de la Edad Media, la "Virgen", junto con la "Pecadora" constituyen dos devociones ligadas directamente a la peregrinación, siendo quizá los prototipos femeninos más representados a lo largo del Camino de Santiago, que en buena medida reflejan lo que la iglesia pensaba acerca de la mujer en el medievo; véase: CENDÓN FERNÁNDEZ, Marta, "Mujer, peregrinación y arte en el Camino de Santiago. ¿Ave y Eva?". Monografías 11 de Cuadernos de Estudios Gallegos. Carlos Andrés González Paz (Ed.). Santiago de Compostela, 2010, pp. 155-179.

33 RODRÍGUEZ GONZÁLEZ, Ángel, "El hospital de San Miguel", p. 227. OTERO TÚÑEZ, Ramón, "Santa María del Camino", p. 110.

${ }^{34}$ HOYO, Jerónimo del, Memoria, p. 87.

35 LÓPEZ FERREIRO, Antonio, (Transc.), “Testamento de Da Urraca de Moscoso”, pp. 440-441. 
un escudo partido por una banda con tres veneras, que nada tiene que ver con los $\operatorname{Moscoso}^{36}$.

Como veremos más adelante, también las tumbas que estaban en el cuerpo de la iglesia y en el coro fueron desmanteladas en el año 1619, al mismo tiempo que se abrían nuevas sepulturas a la entrada de la iglesia de las que hoy tampoco queda nada. Se conservó, sin embargo, la capilla funeraria que actualmente se conoce con el nombre de los marqueses de Camarasa o de los condes de Amarante, por los descendientes de los Neira y Luaces que fueron en realidad sus primeros patrocinadores y también los primeros en enterrarse en dicho lugar ${ }^{37}$.

\section{Los Neira de Luaces de la ciudad de Santiago de Compostela y la funda- CiÓN DE LA CAPILla FAMILIAR EN LA IGLESIA dE SANTA María do CAMiÑo.}

En el año 1561, el regidor de la ciudad de Santiago Gonzalo de Otero de Luaces (Gonzalo el Mozo), en su testamento firmado el mismo día de su muerte que acaeció en la madrugada del 7 de septiembre de ese mismo año, mandó "[...] que cuando dias fuere finado de me llevar desta vida presente, mi cuerpo seya sepultado en la capilla junto a la capilla de Santa María del Camino la qual fizo, fundo e hedifico Juan de Uteyro vecino e regidor que fue desta ciudad defunto que aya gloria que la qual dicha capilla e dentro della mando me digan por siempre jamas

36 OTERO TÚÑEZ, Ramón, “Santa María del Camino”, pp. 110 y 122. Otero Túñez se pregunta si la veneras de este escudo podrían considerarse "signos parlantes del Camino", segundo apellido de Juán Vidal, abuelo de Ruy Sánchez. Sin embargo aunque entre las armas del linaje de ese apellido figuran las veneras, lo cierto es que ninguna de las variantes de su escudo coincide con éste de la iglesia de Santa María; véase: GARCÍA CARRAFA, Alberto - GARCÍA CARRAFA, Arturo, Enciclopedia heráldica y genealógica hispano-americana, tomo 19, Madrid, 1925, pp. 194-195, lámina 10. Valero de Bernabé dice que las veneras solas o combinadas con otras figuras heráldicas, son frecuentes en muchos linajes gallegos; añade este autor, que su distribución por comunidades españolas refleja la gran influencia que tiene la tradición jacobea y así, las tres comunidades donde más abundan son Galicia, Navarra y Vascongadas, todas ellas atarvesadas por las distintas rutas jacobeas. VALERO DE BERNABE Y MARTIN DE EUGENIO, Luis, Simbología y diseño de la heráldica gentilicia galaica. Madrid, 2003, pp. 197-199 y 505. Por otra parte hay que decir que las armas del apellido Pelegrin, son similares a las del escudo en cuestión; los Pelegrí de la casa de Lérida, los Pelegrin de Aragón y los Pelegri o Pelegrin o Pelegrino de Italia, traen en campo de azur, una banda de plata cargada de tres veneras de gules; véase: GARCÍA CARRAFA, Alberto - GARCÍA CARRAFA, Arturo, Enciclopedia, tomo 69. Madrid, 1957, p. 222, lámina 6. Los Pelegín, Peleguín o Peleriz, presentes en Galicia, llevan en campo de azur, una banda de plata cargada de tres veneras al natural. Su lema es: "Peregrinar por la honra"; véase: CRESPO DEL POZO, José Santiago, Blasones, p. 163. La presencia de este escudo en Santa María, nos recuerda que es más que probable que la iglesia sirviese como lugar de enterramiento a algunos de los fallecidos en el hospital de San Miguel.

${ }^{37}$ Los descendientes de los Luaces de Neira asumieron el condado de Amarante a finales del siglo XVII y ya en el siglo XVIII, el marquesado de Camarasa. EL ARCHIVO DUCAL DE MEDINA$C E L I$, en: http://www.fundacionmedinaceli.org 
una misa rezada en cada día lunes por la mi anima e demás antepasados [...]"38. Gonzalo el Mozo dejó por cumplidores de su manda y testamento a su segunda mujer María de Neira, a Lopo Diaz de Gayoso y Gómez Álvarez de Cardoso, secretario de la Real Audiencia. Un mes más tarde, en octubre de 1561, la viuda de Gonzalo -María de Neira- es nombrada tutora de sus hijos ${ }^{39}$.

La capilla a la que se refiere el testamento permanece todavía en pie. Fue construida en estilo gótico ojival tardío ${ }^{40}$. La edificación constituye un cuerpo independiente de planta rectangular, que se adosa al lado Norte de la cabecera de iglesia de Santa María do Camiño; en sus primeros tiempos funcionó como sacristía. En ella puede verse formando parte del enlosado, una pieza correspondiente a una lápida sepulcral de granito (fig. 2) que conserva una inscripción en parte repicada, en la que aún puede leerse con cierta claridad:

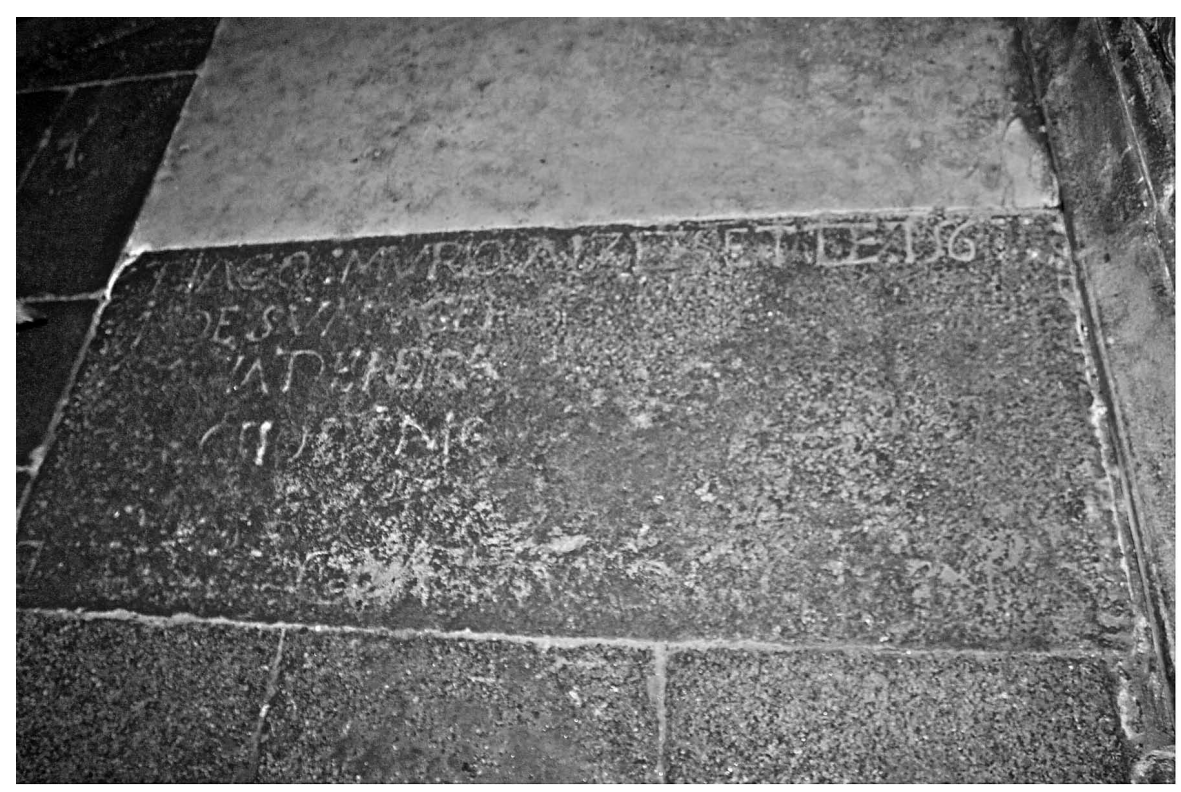

Fig. 2

Lápida sepulcral de Gonzálo de Luaces el Mozo en la capilla de los Neira de Luaces en "Santa María do Camiño" (Santiago de Compostela)

38 AHUS. Sección de Protocolos. Libro de testamentos. Testamento, cumplimiento, recuento de bienes y curadoría de Gonzalo de Luaces, regidor de la ciudad de Santiago. S-139, fols. 9v y 20r. 39 AHUS. Sección de Protocolos. Libro de Testamentos. Testamento, cumplimiento, recuento de bienes y curadoría de Gonzalo de Luaces, regidor de la ciudad de Santiago. S-116, fols. 4v-6v. 40 CAAMAÑO MARTÍNEZ, Jesús María, Contribución al estudio del gótico en Galicia (diócesis de Santiago). Valladolid, 1962, p. 305; cit en: OTERO TÚÑEZ, Ramón, "Santa María", p. 111. 


\section{:TIAGO:MVRIO A 7DE SET:DE:156[...] \\ I DE SVA MVGER [...] \\ [...]IA DE NEIRA \\ [...] $\mathrm{MO}$}

La información que aporta la inscripción -aunque incompleta- es coincidente con lo dicho en el testamento de Gonzalo de Luaces el Mozo, por lo que con toda probabilidad esta losa debió pertenecer a su enterramiento. Parece estar fuera de su emplazamiento originario habiendo sido reaprovechada para pavimentar la capilla. A esta pieza cuando menos, le acompañaría otra pieza más, donde figurase el nombre del finado y el cargo que desempeñó como regidor de la ciudad Santiago, de cuyo tóponimo podemos leer las dos últimas sílabas escritas en el extremo superior izquierdo del épigafe. Es muy posible que esta losa formase parte del frontal de una yacija funeraria que originariamente podría estar empotrada en uno de los dos arcosolios que tiene la capilla en el muro norte. El estilo y la disposición de tal enterramiento tendría paralelos en otros sepulcros coetáneos, que aún podemos ver en distintas iglesias y capillas de la ciudad compostelana ${ }^{41}$.

Gonzalo el Mozo estuvo casado en primeras nupcias con María Pérez; de este matrimonio nació Francisco de Luaces. De su segundo matrimonio con María de Neira nacieron Juan de Otero (también llamado, Juan de Neira de Luaces), Juana de Neira y Catalina de Neira (también llamada Catalina Vargas, como su abuela materna $)^{42}$.

María de Neira era hija de Juan de Otero, quien -como acabamos de ver- es señalado en el testamento de Gonzalo el Mozo, por ser el fundador de la capilla familiar de la iglesia Santa María. Este último dato permite retrotraer la fecha de construcción de dicha capilla a la primera mitad del siglo XVI, cuando el padre de María de Neira ejerció como regidor de la ciudad de Santiago ${ }^{43}$.

\footnotetext{
${ }^{41}$ En concreto nos fijamos en el sepulcro de Fructuoso Gallos que falleció en el año 1564, poco después que Gonzalo de Luaces el Mozo y al igual que éste, ejerció el cargo de regidor de la ciudad de Santiago. Fructuoso Gallos fue enterrado junto con su mujer Isabel de Monteser, en la capilla del Espíritu Santo de la catedral compostelana, en un lucillo de corte gótico abierto en el muro de la epístola, donde se dispuso una yacija que tiene una inscripción al frente partida por el escudo de armas; véase: CHAMOSO LAMAS, Manuel, Escultura funeraria en Galicia. Orense, 1979, pp. 554-555.

42 AHUS. Sección de Protocolos. Libro de testamentos. Testamento, cumplimiento, recuento de bienes y curadoría de Gonzalo de Luaces, regidor de la ciudad de Santiago. S-139, fols. 21v.

${ }^{43}$ La información contenida en los documentos del Archivo Histórico Universitario, que hemos citado más arriba, junto con los datos que aporta la lápida funeraria de Gonzalo de Luaces el Mozo, contradicen en lo fundamental a lo dicho primero por Fernández de Henestrosa y por el padre Padre Crespo después, en cuanto a que ambos autores afirman que en el año 1562, Gonzalo de Luaces el Mozo y su mujer María de Neira, fundaron la capilla de la casa, dentro de la iglesia parroquial de
} 
Juan de Otero fue hijo de Diego de Neira y estuvo casado con Catalina de Vargas. Crespo del Pozo dice de él que adquirió numerosas tierras y propiedades entre los años 1537 y $1541^{44}$. De los Neira nos dicen los García Carrafa que era apellido gallego originario de la provincia de Lugo, en donde tuvieron antiguas casas hidalgas, particularmente en los partidos judiciales de Becerreá y de Sarria. Es muy posible que Juan de Outeiro y Gonzalo de Luaces el Mozo estuviesen emparentados antes de que llegasen a ser suegro y yerno respectivamente, ya que a la coincidencia de los apellidos se añade la procedencia común de ambos, en tierras lucenses.

En la parroquia de Santa María de Luaces (ayuntamiento de Pol, provincia de Lugo), establecen los García Carrafa el primitivo solar del apellido Luaces, cuyas armas serían: “[...] De azur, con cinco estrellas de oro, una en abismo, surmantada de un creciente ranversado, de plata, y las otras cuatro en los ángulos del escudo [...]"45.

En el Manuscrito de Francisco de Mújica se dice que el origen de los Luaces estuvo en la casa de los Suevos de Luaces y en la casa de Castro de Luaces, en la susodicha feligresía de Santa María Luaces. Al parecer, ambas casas tuvieron en un principio un mismo señor y fundador. De aquí descenderían los Luaces de la ciudad de Santiago por línea recta de varón, que fue Diego Arias de Luaces. Uno de los hijos de Diego Arias, Gonzalo de Luaces el Viejo, oidor del reino de Ga-

\footnotetext{
Santa María do Camiño; añade el padre Crespo que en ese mismo año se convinieron ambos esposos con los feligreses de la parroquia para efectuar dicha fundación y que no sería hasta el tiempo de D. Andrés Gayoso (muerto en el año 1731), que se hiciese la cesión completa de la capilla. Tampoco sería posible como asegura el Padre Crespo que Gonzalo el Mozo, testase ante el notario Gonzalo de Puñal el día 16 de enero del año 1562, dando poder a su esposa María de Neira para que lo hiciese en su nombre, ni que pudiera existir un codicilo de este testamento, fechado el 5 de octubre del año 1564. Por último, tampoco puede aparecer la firma de Gonzalo el Mozo, en el inventario de los bienes que habían quedado de su padre Gonzalo de Luaces el Viejo, fechado -según Crespo- el día 15 de ocubre de 1561. FERNÁNDEZ DE HENESTROSA Y ORTIZ DE MIOÑO, Ignacio, Apuntes para el historial de la casa de Camarasa. San Sebastián, 1934, p. 243. CRESPO DEL POZO, José Santiago, Blasones, pp. 8 y 10. Los García Carrafa apuntan sin embargo, que fue Juan de Otero Neira quién fundó la capilla de Santa María do Camiño, capilla en la que dicen, se conservan los sepulcros de estos Neira (del propio Juan de Outeiro de Neira y de su hija María de Neira). Los autores no se extienden más en el tema, ni indican tampoco las fuentes de información; GARCÍA CARRAFA, Alberto - GARCÍA CARRAFA, Arturo, Enciclopedia, tomo 62. Madrid, 1956, p. 6. Posteriormente, Seijas Vázquez repite al pie de la letra los mismos datos que aporta García Carrafa; SEIJAS VÁZQUEZ, Eduardo, "Neira". Gran Enciclopedia Gallega, tomo 22. Silverio Cañada (Ed.), Santiago-Gijón, 1974, p.150.

${ }^{44}$ GARCÍA CARRAFA, Alberto - GARCÍA CARRAFA, Arturo, Enciclopedia, tomo 62. Madrid 1956, pp. 6-7. CRESPO DEL POZO, José Santiago, Blasones, pp. 5-7. EL ARCHIVO DUCAL DE MEDINACELI, en: http://www.fundacionmedinaceli.org

45 GARCÍA CARRAFA, Alberto - GARCÍA CARRAFA, Arturo, Enciclopedia, tomo 51. Madrid 1953, pp. 254-255. Lámina 9.
} 
licia, fue el primero en venir a Santiago, donde se casó. Él y su hermano Fernando estuvieron al servicio y bajo la protección de Rodrigo Osorio de Moscoso, conde de Altamira ${ }^{46}$.

El hijo primogénito de Gonzalo el Viejo, fue Gonzalo de Luaces, segundo de ese nombre (Gonzalo el Mozo); su hijo Juan de Neira de Luaces, tomaría el apellido de Outeiro por la "Casa de Outeiro de Luaces de Sobrado", próxima a Mondoñedo; en la Real Cancillería de Valladolid se depositaron en 1594 las probanzas de su hidalguía ${ }^{47}$. Juan de Neira Luaces, al igual que su padre y su abuelo, fue también regidor de la ciudad de Santiago y se casó con María de Mendoza, hija de Pedro Bermúdez de Castro y hermana de Fernando Bermudez de Castro, señor de la casa torre de Nogueira, en tierra de Bergantiños ${ }^{48}$.

Gonzalo de Luaces el Mozo y su segunda mujer María Neira estaban afincados muy cerca de la iglesia de Santa María, en calle de la Algalia de Abajo, transversal de la "rúa do Camiño". Tenían allí una "casa de morada" -que según el Crespo- fue comprada por el matrimonio poco después de su boda, celebrada en el año $1546^{49}$. En su solar se construiría posteriormente uno de los mejores palacios de la ciudad de Santiago, levantado por sus descendientes y conocido como palacio de los marqueses de Camarasa o de Amarante. En dicha casa es donde testa y muere Gonzalo de Luaces; en su testamento consta que él mismo, junto con su mujer María de Neira, hacen vínculo y mayorazgo con los bienes de ambos y nombran sucesor a su hijo Juan de Neira Luaces y a sus legítimos descendientes, estableciéndose las condiciones a las que estaba sujeta la sucesión y dejando el usufruto a María de Neira ${ }^{50}$.

Unos años después, concretamente en 1586, María acrecentó el patrimonio familiar comprando el coto y jurisdicción de Oca, que el rey Felipe II había desmembrado de la dignidad arzobispal de Santiago. En el año 1600 fundó nuevo mayorazgo en el que se incluían su "Señorío y Casa de Oca", declarando primer sucesor a su hijo Juan y después de éste a sus legítimos herederos, exigiendo que llevasen sus apellidos y las armas que describe en su testamento

46 BOUZA-BREY TRILLO, Fermín, "El origen”, pp. 230-234.

47 Ibidem, p. 232.

48 FERNÁNDEZ DE HENESTROSA Y ORTIZ DE MIOÑO, Ignacio, Apuntes, p. 243. MARTÍNEZ BARBEITO, Carlos, Torres, pazos y linajes de la provincia de La Coruña. La Coruña, 1978, pp. 262-264. LÓPEZ GÓMEZ, Pedro, "Historia del pazo de Oca". Boletín Auriense, tomo 14-15 (1986), p. 152. CRESPO DEL POZO, José Santiago, Blasones, p. 10. EL ARCHIVO DUCAL DE MEDINACELI, en: http://www.fundacionmedinaceli.org

49 CRESPO DEL POZO, José Santiago, Blasones, p. 8.

50 AHUS. Sección de Protocolos. Libro de testamentos. Testamento, cumplimiento, recuento de bienes y curadoría de Gonzalo de Luaces, regidor de la ciudad de Santiago. S-139, fols. 15 v y 16 r. 
como " $[. .$.$] de gules, con una cruz floreteada de plata y en la punta un caldero$ de plata $[\ldots], 51$.

En esos momentos la urbe santiaguesa era refugio destacado de la sociedad estamental, con una presencia de hidalgos que superaba la media de la cota nacional. Al lado de éstos y al menos hasta mediados del siglo XVII (momento en que cambian las circunstancias), existía un grupo de mercaderes muy activo que comerciaba intercambiando productos locales, del resto de España, de Europa y también de la Carrera de Indias. Por entonces la familia de los Luaces había logrado ya situarse a la cabeza entre los más adinerados de la ciudad; para Gelabert Gónzalez, constituyen el paradigma de los burgueses que amasaron su fortuna en el comercio y que al cabo de no más de tres generaciones, terminarían convirtiéndose en hidalgos y grandes señores rentistas, que progresivamente habrían ido transformando el capital móvil (producto de la actividad mercantil), en capital fundiario dependiente principalmente de los bienes de la tierra.

En ese proceso de cambio y ascenso eran imprescindibles las relaciones familiares en cuanto a política matrimonial se refiere, las relaciones interpersonales de carácter socio-económico y las relaciones políticas en el ámbito del gobierno municipal $^{52}$. Así por ejemplo, ser regidor de Santiago suponía estar integrado en el aparato fundamental del poder de la ciudad y disponer por ello, de una plataforma de promoción de primer orden. En principio, el cargo de regidor perpetuo pertenecía en propiedad a su titular por concesión real, formaba parte del patrimonio familiar y estaba reservado a la oligarquía nobiliaria; se estimaba como una distinción honorífica adicional, ya que su ejercicio resultaba ser sumamente gravoso. Esto último explica que con el tiempo gentes de procedencia plebeya se fuesen infiltrando en la composición del cabildo de regidores gracias a su fortuna personal $^{53}$.

En ese mismo juego de relaciones, el patrocinio de capillas constituía una práctica que prestigiaba a quién la llevaba a término y era claro reflejo del éxito alcanzado por algunas familias, que con ello disfrutaban de ciertos privilegios y

\footnotetext{
51 FERNÁNDEZ DE HENESTROSA Y ORTIZ DE MIOÑO, Ignacio, Apuntes, p. 242. GARCÍA CARRAFA, Alberto - GARCÍA CARRAFA, Arturo, Enciclopedia, tomo 62. Madrid 1956, pp. 67 y 11, lámina 1. CRESPO DEL POZO, José Santiago, Blasones, pp. 7 y 10. LÓPEZ GÓMEZ, Pedro, "Historia", p. 152. EL ARCHIVO DUCAL DE MEDINACELI, en: http://www.fundacionmedinaceli.org. Añaden los García Carrafa que otros Neira ponen bajo la cruz, en la punta de ese escudo, cuatro veneras de plata en vez del caldero y otros más -también en Galicia- pintaron de plata el campo; la cruz floronada, de gules y cargada de cuatro veneras de plata, poniendo en la punta ondas de agua de azur y plata.

52 GELABERT GONZÁLEZ, Juan Eloy, Santiago, pp. 270-289.

53 LÓPEZ DÍAZ, María, “Aportación al estudio de los oficios públicos en la ciudad de Santiago a mediados del siglo XVIII". Compostellanum. Sección de Estudios Jacobeos, vol. 31, n 3-4 (1986), pp. 418 - 420 y 435 .
} 
gratificaciones, como eran el derecho a ocupar los bancos principales del templo y el derecho de sepultura en su interior; incluso podía ser inicio para acreditar la hidalguía. Precisamente el afán por afirmar la cohesión y posición social del grupo familiar de pertenencia y el deseo de transmitir y perpetuar el orgullo y la memoria del linaje explica la heraldización del espacios funerarios, fenómeno -que como veremos- es más que evidente en la capilla de los Neira de Luaces.

En la mentalidad de época, todo ello iba unido a la obtención de beneficios espirituales. No sólo se trataba de construir y dotar determinados recintos, sino que además las capellanías eran un tipo de fundaciones eclesiásticas privadas (con origen en la Edad Media y típicas del Antiguo Régimen), por las que se vinculaba a perpetuidad un conjunto de bienes materiales (casi siempre raíces), con la obligación de cumplir con las cargas espirituales, estipuladas por el fundador, entre las que indispensablemente se encontraban un determinado número de misas. Las capellanías implicaban además indudables ventajas fiscales y se hacían en muchos casos para evitar la merma de los bienes vinculados, beneficiándose del usufructo ${ }^{54}$.

Una lápida sepulcral, que se conserva en el colateral del lado del evangelio de la iglesia de San Miguel dos Agros de Santiago, nos ofrece una idea muy clara del carácter, origen y finalidad de este tipo de fundaciones: "In nomine Domini. Amen. Aquí jasen Domingo Yanes, tendeiro e a sua muller María Fernández, que deijaron rendas e posesiones por suas almas para sempre que un capellán diga misa en todas las horas del día en esta capilla de San Miguel e o día que no fecera o rector o debe acusar por lo dejar e que perga a capellanía . Era M. LCCVII. ${ }^{\circ}$ mensis decembris." 55 (fig. 3).

En los siglos XVI y primera mitad del XVII, tanto en la catedral compostelana, como en muchas otras iglesias y monasterios de Santiago se multiplican los ejemplos de capellanías y así nos encontramos con que un primo de Gonzálo el Mozo, Bernardo de Luaces (del que hemos hablado más arriba, al referirnos a su residencia frente a las Casas Reales), fundó también una suntuosa capilla en el convento de San Francisco, donde tuvo "[...] su entierro con cargo de siete misas perpetuas en cada semana [...]"56.

\footnotetext{
${ }^{54}$ FERNÁNDEZ CUBEIRO, Eugenia, "Una práctica de la sociedad rural: aproximación al estudio de las capellanías de la diócesis compostelana en los siglos XVII y XVIII". La historia social de Galicia en sus fuentes de protocolos, Antonio Eiras Roel (Dir.) Santiago de Compostela, 1981, pp. 205-215.

55 HOYO, Jerónimo del, Memoria, p. 86. Jerónimo del Hoyo transcribe incorrectamente la era, que en realidad es: MCCCLXXIIII (año 1336).

56 BOUZA-BREY TRILLO, Fermín, "El origen”, p. 233.
} 


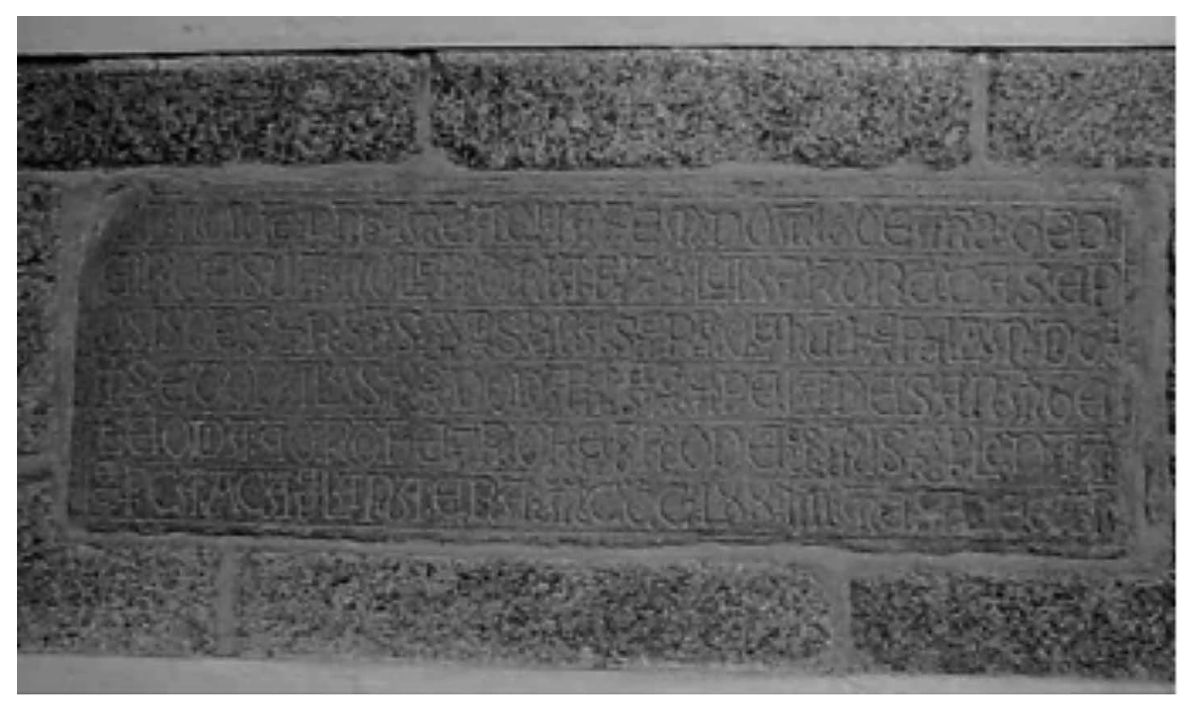

Fig. 3

Lápida sepulcral de Domingo Yánez y su mujer en la iglesia de "San Miguel dos Agros"

(Santiago de Compostela)

Como hemos visto, en el caso de los Neira de Luaces la capilla fue eregida por el fundador Juan de Outeiro. Posteriormente los bienes ligados a ella y el derecho de patronato fueron transmitidos a los sucesivos miembros de la familia que heredaron el mayorazgo. Se trataría, pues, de una capellanía laical en la que la iglesia ejercería un papel de vigilancia del cumplimiento de las cargas fundacionales, con la simple aceptación por parte del ordinario. Quizá fuese ésta, la razón por la que el visitador arzobispal Jeronimo del Hoyo no hace mención de ella en su Memoria, cuando habla de la iglesia de Santa María do Camiño.

3. El CONJUNTO ARQUITECTÓNICO, ESCULTÓRICO, PICTÓRICO Y HERÁLDICO DE LA CAPILla de los NeIRA DE LuACES .

La construcción y dotación de las capillas funerarias privadas actuó como un elemento más, capaz de dinamizar la producción artística de la ciudad de Compostela. En ellas trabajaron canteros, escultores, entalladores y pintores locales, que se formaron y emplearon al abrigo de los grandes maestros que por entonces se hallaban en Santiago realizando obras de gran envergadura en los principales edificios de la ciudad. La notable renovación urbana que experimentó Santiago a partir del siglo XVI como centro religioso y cultural de Galicia que era, dio cabida a la proliferación de talleres de artistas y artesanos de muy variado alcance, que encontraron mecenazgo no sólo entre los clérigos y religiosos, sino también 
entre la élite laica representada por las grandes casas nobiliarias, junto a otros títulos menores y también por los burgueses más destacados de la urbe.

Los encargos que solía hacer éste último grupo se centraban principalmente en sus casas y palacios urbanos, en las capellanías de su propiedad y también en sus fortalezas, ya que en este período muchas de ellas se reformaron para adaptarlas a las exigencias de los nuevos tiempos. Así a comienzos del siglo XVI, Rodrigo Osorio de Moscoso, segundo conde Altamira (aquel que acogió en Santiago, a los hijos de Diego Arias de Luaces), agrandó la construcción del castillo de Altamira en Brión, que llegó a contar por entonces con un palacio "[...] de cuyas dimensiones y ornamentación quedó larga y encomiástica memoria [...]" según dice Martínez Barbeito ${ }^{57}$. Entre las ruinas del palacio, aún puede verse una portada con arco apuntado de amplio dovelaje y sobre ella una ventana adornada con arco conopial. En el año 1616, el maestro cantero Domingo Álvarez Ferraz aparece participando en una puja para efectuar diversas obras en la fortaleza de Altamira. Anteriormente -concretamente en el año 1608- este maestro figuraba como aparejador de las obras del monasterio de San Martín Pinario, en Santiago. En 1615, el arquitecto Gaspar Arce Solórzano le cedió la mitad de la obra del puente de Fillaboa; además trabajó en el coro y claustro del monasterio de San Paio de Antealtares, en las fuentes del Hospital Real de Santiago y, como veremos más adelante, en las capillas familiares del Santo Cristo, en la iglesia de Santa María Salomé y del Buen Jesús, en la iglesia de San Benito ${ }^{58}$.

También la antigua fortaleza de Oca (que como hemos visto más arriba, fue adquirida por María de Neira a finales del siglo XVI) fue rehablitada posteriormente por sus distintos dueños y señores, hasta llegar a ser en los siglos XVII y XVIII, uno de los "pazos" rurales más conocidos y destacados de Galicia tanto por su arquitectura, como por sus estanques y jardines ${ }^{59}$.

Por lo que respecta a las capillas funerarias, se conservan en la ciudad de Santiago algunas edificaciones de este tipo y carácter, que -al igual que la fundada por Juan de Outeiro en Santa María do Camiño- fueron construidas en estilo gótico ojival tardío.

\footnotetext{
57 MARTÍNEZ BARBEITO, Carlos, Torres, pp. 47-48.

58 PÉREZ CONSTANTI, Pablo, Diccionario de artistas que florecieron en Galicia durante los siglos XVI y XVII. Santiago, 1930, p. 12. GOY DIZ, Ana, A actividade, vol. 1, docs. 40, 45, 99, 111, 371 y 658 , pp. 96-97, 99, 124-125, 130-131 y 252-253.

59 ODRIOZOLA, Antonio, "Pazo de Oca". Gran Enciclopedia Gallega, t. 23. Silverio Cañada (Ed.), Santiago-Gijón, 1974, p. 15. REIMÓNDEZ PORTELA, M., Guía Turística de La Estrada. [S.1.], 1976, pp. 86-88. LÓPEZ-CHAVES MELÉNDEZ, Juan Manuel - AMOR MORENO, Grato Ernesto, Inventarios de Pazos y Torres de la Provincia de Pontevedra, tomo 2 , vol. 6. (Estrada, Deza y Camba). Vigo, 1982, pp. 31-33. LÓPEZ GÓMEZ, Pedro, "Historia", pp. 155 y 161-167. CASTILLO LÓPEZ, Ángel del., Inventario, p. 382. REIMÓNDEZ PORTELA, Manuel, A Estrada Rural. Pontevedra, 1990, pp. 195-199.
} 
Una de ellas es la capilla dedicada a Nuestra Señora y a San José que se encuentra inmediata al presbiterio de la iglesia parroquial de Santa María Salomé, en el lado de la epístola; fue levantada en torno al año 1573, es de planta cuadrangular y está cubierta por una bóveda de crucería estrellada, con una clave central que ostenta las armas de los que fueron sus fundadores Lope de Losada y su mujer Teresa Gómez Mosquera ${ }^{60}$. Junto a esta capilla está la del Santo Cristo, cubierta igualmente por una bóveda de crucería estrellada; fue construida por el susodicho maestro cantero Domingo Álvarez Ferraz para el capitán y ejecutor de la Audiencia Arzobispal de Santiago, Juan González Becerra de Nebra ${ }^{61}$. El mismo maestro firma en 1608 el correspondiente contrato para hacer la capilla del Buen Jesús en San Benito del Campo, para Catalina Oanes ${ }^{62}$. En la iglesia parroquial de San Miguel dos Agros hay otra capilla llamada de Nuestra Señora y San Jerónimo, que tiene también una bóveda de crucería estrellada del siglo XVI con cinco claves colgantes; esta capilla fue fundada por el capitán Jerónimo de Tobes ${ }^{63}$.

La capilla de los Neira de Luaces tiene planta rectangular distribuida en dos tramos cubiertos con sendas bóvedas de crucería de arcos apuntados (fig. 4); los soportes o aristones de las bóvedas se apoyan en sencillas ménsulas que sobresalen de la pared a media altura (fig. 5); la excepción la constituye el aristón central del lado sur, ubicado entre los los dos arcos de la entrada, que se sustenta sobre una pilastra de sección semicircular (fig. 6). Los aristones se abren en forma de abanico trazando cuartos de círculo tangentes. En el centro de cada una de las

\footnotetext{
${ }^{60}$ HOYO, Jerónimo del, Memoria, p. 84. YZQUIERDO PERRÍN, Ramón, "Os templos parroquiais. Santa María Salomé". Santiago de Compostela. Patrimonio Histórico Gallego I. Ciudades, vol. 2. Xosé Manuel García Iglesias (Dir.). Laracha (A Coruña), 1993, p. 186-187. SORALUCE BLOND, José Ramón, FERNÁNDEZ FERNÁNDEZ, Xosé, Arquitecturas, pp. 90-91.

${ }^{61}$ En el año 1626 se efectuaron diversos pagos por esta obra, GOY DIZ, Ana, A actividade, vol. 1, doc. 44, pp. 98. Esta misma capilla aparecerá posteriormente nombrada como "Capilla de los Becerras"; COUSELO BOUZAS, José, Galicia artística, p. 572. Por su parte Yzquierdo Perrín señala que puede ser una de las capillas que cita Jerónimo del Hoyo al hablar de Santa María Salomé: o bien la dedicada a San Idelfonso o bién a San Pedro, fundadas por Juan Martínez de Moedanoba, la primera y por Juan Alfonso Míguez, la segunda; YZQUIERDO PERRÍN, Ramón, “Os templos parroquiais. Santa María Salomé”, p. 187.

62 GOY DIZ, Ana, A actividade, vol 1, docs. 33, 658, 680 y 1295, pp. 94, 369, 376-377, 657.

${ }^{63}$ HOYO, Jerónimo del, Memoria, p. 86. BARREIRO VÁZQUEZ VARELA, Bernardo, Guía histórica, $\mathrm{n}^{\circ} 30$ del texto adjunto al mapa. LÓPEZ Y LÓPEZ, Román, Santiago de Compostela, $\mathrm{p}$. 182. CASTILLO LÓPEZ, Ángel del, Inventario, p. 557. FILGUEIRA VALVERDE, José, Santiago de Compostela, p. 98. YZQUIERDO PERRÍN, Ramón, "Templos parroquiais. San Miguel dos Agros". Santiago de Compostela. Patrimonio Histórico Gallego I. Ciudades, vol. 2. Xosé Manuel García Iglesias (Dir.). Laracha (A Coruña), 1993, p. 161-162. SORALUCE BLOND, José Ramón - FERNÁNDEZ FERNÁNDEZ, Xosé, Arquitecturas, p. 210. SINGUL LORENZO, Francisco FERNÁNDEZ CASTIÑEIRAS, Enrique, San Miguel dos Agros. Santiago de Compostela. Santiago de Compostela, (D.L. 2001), pp. 8-9.
} 


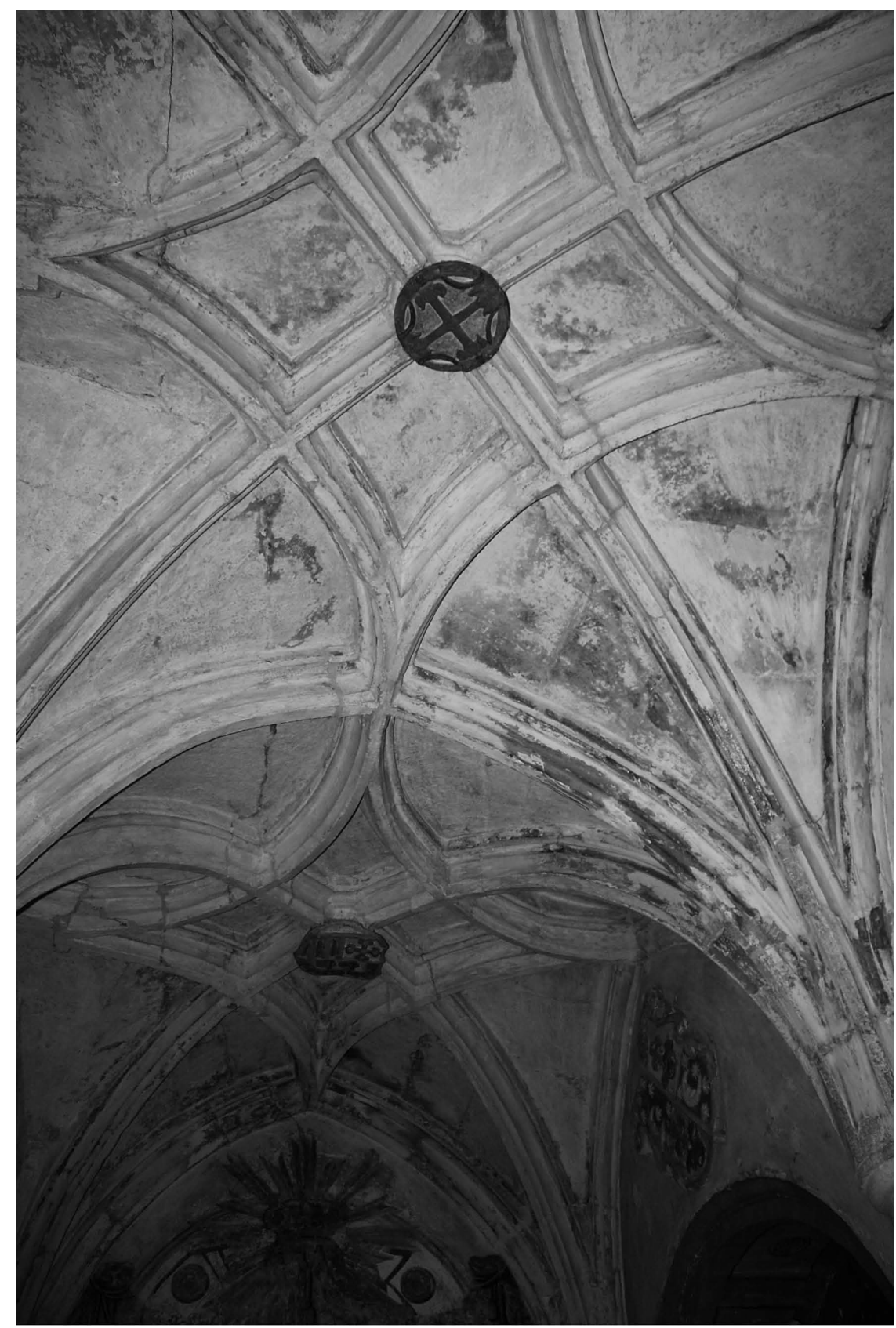

Fig. 4

Bóvedas de la capilla de los Neira de Luaces 


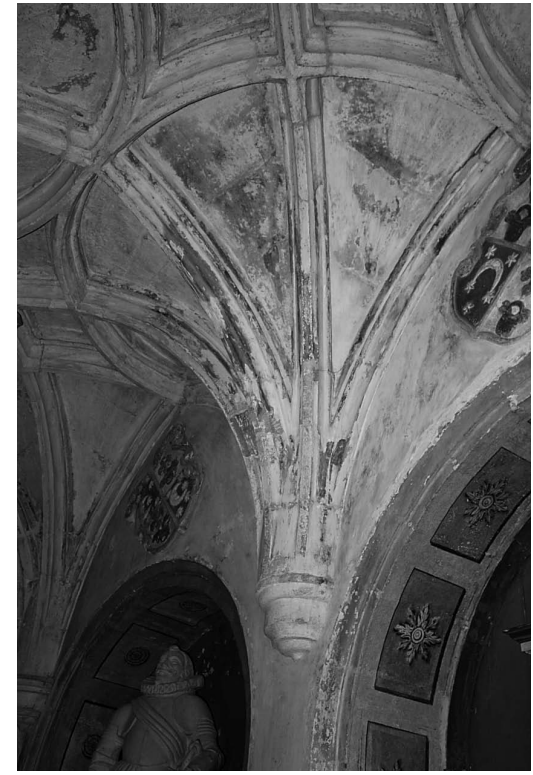

Fig. 5

Aristón sobre ménsula

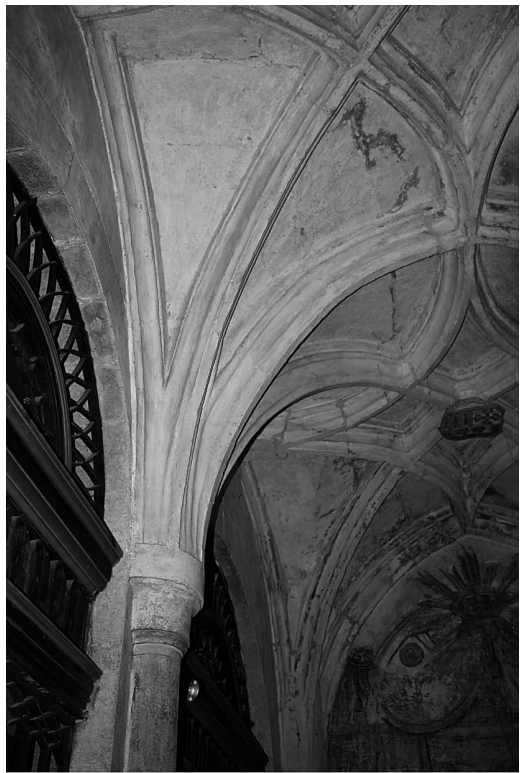

Fig. 6.

Aristón sobre pilastra

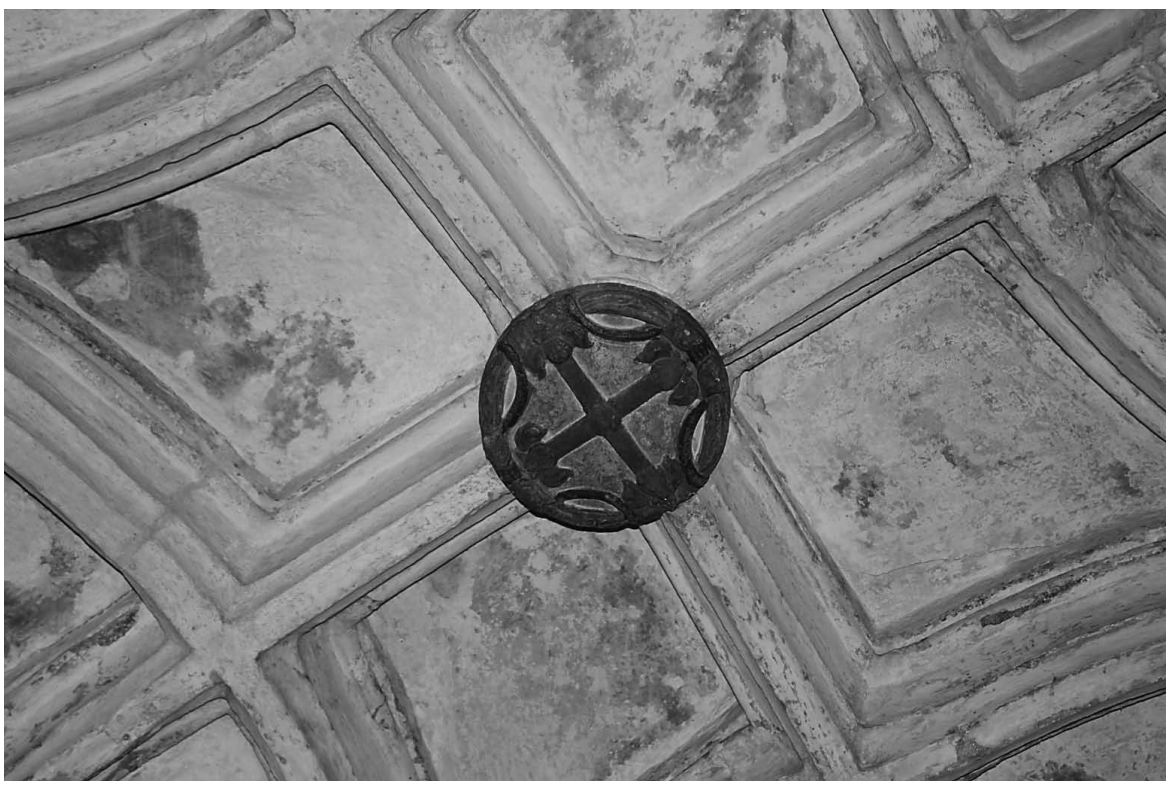

Fig. 7

Cruz floronada, cargada de veneras en la clave de la bóveda oriental de la capilla 


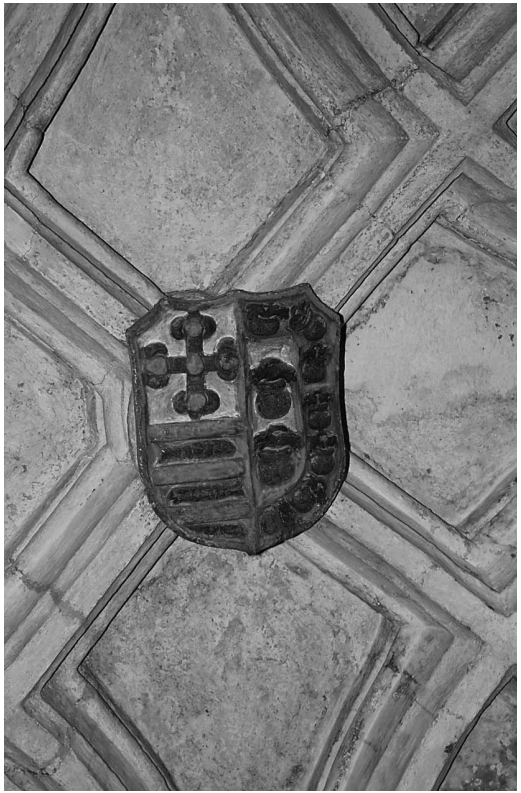

Fig. 8

Escudo superpuesto a la clave de la bóveda occidental de la capilla

bóvedas, los bordes de los círculos dibujan una estrella de cuatro puntas, entrecruzada por las nervaduras de los arcos. Las nervaduras se dinamizan con la alternancia de molduras cóncavas y convexas, que les confieren un acusado relieve.

La clave de la bóveda oriental de la capilla, se orna con la cruz floronada y cargada de cinco veneras de los Ribadeneira $^{64}$ (fig. 7), mientras que a la clave de la bóveda del lado de poniente se le sobrepuso en época posterior a su construcción, un escudo partido (fig. 8). En el primer cuartel de este escudo se distingue la cruz floronada cargada de veneras y debajo las fajas y los peces de los Gayoso. En el segundo cuartel se disponen dos calderos con sierpes y una bordura con otros siete calderos semejantes, cuya atribución no puede precisarse ${ }^{65}$. Por su tipología este escudo puede ser datado en las últimas décadas del siglo XVI o en las primeras del siglo XVII, lo que permite relacionarlo en un momento próximo al entronque de los Neira y Luaces con los Gayoso y Noguerol ${ }^{66}$.

Hoy en día las bóvedas de la capilla de los Neira de Luaces están recubiertas con cal, excepto en lo que atañe a los emblemas heráldicos, que aparecen repintados en ocre, rojo, verde y oro. Es muy posible que originariamente se concibiese

${ }^{64}$ Otra cosa es que aquí pudiera reinterpretarse como propio de los Neira.

65 No se puede descartar que las armas contenidas en el segundo cuartel sean una interpretación tardía, libre y nada ortodoxa, de las armas de los Neira, o acaso de los Noguerol. En este caso, no hemos tenido en cuenta los esmaltes, pues se advierte que esta labra fue repintada en tiempos posteriores a su elaboración.

${ }^{66} \mathrm{Al}$ morir Gonzalo de Neira y Luaces Bermúdez de Castro sin tener descendencia, heredó el señorío de Oca su hermana Catalina, quién se casó con Juan de Gayoso Noguerol Prado y Gato, álferez y regidor de la ciudad de Orense. Este caballero testó en la misma ciudad de Orense el 6 de abril del año 1652, dejando heredero de sus señoríos a su hijo Juan Gayoso Noguerol y Mendoza; véase: FERNÁNDEZ DE HENESTROSA Y ORTIZ DE MIOÑO, Iganacio, Apuntes, p. 243. CRESPO DEL POZO, José Santiago, Blasones, p. 11. LÓPEZ GÓMEZ, Pedro, "Historia del pazo”, p. 152. CADENAS Y VICENT, Vicente de, Caballeros de la Orden de Calatrava que efectuaron pruebas de su ingreso durante el siglo XVIII, tomo 2. Madrid, 1987, p. 17. EL ARCHIVO DUCAL DE MEDINACELI, en: http://www.fundacionmedinaceli.org

${ }^{67}$ PÉREZ CONSTANTI, Pablo, Diccionario, p. 409. 
dotar a todo el conjunto arquitectónico de policromía, como era propio del estilo de la época. Sabemos con certeza que en el año 1537 el pintor Pedro Noble (o Nobre) contrató en veinte ducados la obra de pintura al temple de la capilla mayor de Santa María do Camiño y además dos escudetes de armas de la manera “[...] que están de bulto en los monumentos [sepulcros] de la dha capilla [...]". En el contrato se explica con detalle la obra decorativa, en la cual entraban follajes, lazos, racimos, florones, etc ${ }^{67}$. Cabe la posibilidad de que los monumentos, a los que se refiere el documento, sean los de la capilla de Juan de Outeiro que por lo que sabemos, estaba adosada a la cabecera de la iglesia; de ser esto así resultaría que estaría ya construída en esa fecha.

En el año 1605 consta que el regidor de la ciudad de Santiago Juan de Neira de Luaces contrata al cantero Melchor López para que hiciese "[...] un arco de piedra de grano labrada y escodada de la parte de a dentro con un relebo y salisa afuera de quattro de dos de la pared que esta echa, la qual tiene de hacer en la capela que tiene el dicho regidor junto a capilla y Parroquia de Nuestra Señora del Camino y sirve de sacristía [...]"; por el contrato firmado, Melchor López debía efectuar la obra supervisado por oficiales y siguiendo las trazas que le había dado el escultor Juan de Moreiras. Además se especifica lo siguiente: “ [...] la pared que se tiene de derribar para hacer el arco la tiene el dicho Melchor Lopez de hescorar y tiene que dexar segura y fuerte de suerte que por su caussa no aga sintimiento a la dicha pared y harcos, ni cinborio de arriba [...]"68.

El escultor Juan de Moreiras, que aparece en el contrato, es también mencionado en relación a su oficio en varios documentos fechados en 1612, 1631 y $1636^{69}$; en ese último año se le encarga hacer una imagen de San Cristóbal para el retablo de la iglesia de Remesar ${ }^{70}$. En cuanto al cantero Melchor López, encontramos múltiples referencias entre los años 1600 y 1631 que lo sitúan trabajando en el Hospital Real y en otras casas, iglesias y monasterios de la ciudad de Santiago y en su comarca, siendo quizá lo más destacable los paños de pared con sus arcos y los enlosados que realizó en los claustros del colegio de la Compañía de Jesús y del monasterio de Santa María de Conxo ${ }^{71}$. Al mismo cantero se le pagó en el año 1619 por hacer importantes reformas en la propia iglesia de Santa María do Camiño, que consistieron fundamentalmente en "allanar" las sepulturas del coro y del cuerpo de la iglesia, de calear y blanquear el dicho

\footnotetext{
${ }^{68}$ GOY DIZ, Ana, A actividade, vol. 1, docs. 402 y 1110, pp. 266-267 y 574.

${ }^{69}$ PÉREZ CONSTANTI, Pablo, Diccionario, p. 396. GOY DIZ, Ana, A actividade, vol. 1, doc. 949, p. 482.

${ }^{70}$ El patronato y benefios de esta iglesia y también los de San Martín de Riobó, estaban comprendidos en la compra de las tierras y casa de Oca que efectuó María de Neira en 1586.

${ }^{71}$ PÉREZ CONSTANTI, Pablo, Diccionario, p. 339. GOY DIZ, Ana, A actividade, vol. 1, docs. 302,392 y 429 , pp. 216-217, 262 y $279-281$.
} 
coro y de labrar y asentar otras veinte sepulturas en el cementerio de la iglesia, a la entrada ${ }^{72}$.

El contrato establecido entre Juan de Neira y Melchor López nos informa de que la capilla funeraria de los Luaces de Neira funcionó también como sacristía y que a comienzos del siglo XVII, todavía estaban por hacerse las últimas obras para comunicarla y dejarla abiera al interior de la iglesia através del arco trazado por Juan de Moreiras. Esto parece deducirse del hecho de que se diga en el documento, que el arco debía hacerse derribando la parte correspondiente de la pared medianera, sin que la obra afectase a la estabilidad de las demás estructuras del templo, entre las que se mencionan expresamente " [...] la dicha pared y harcos [...]" y también el "[...] cinborio de arriba [...]". La constatación en esos momentos de la existencia un cimborrio en la iglesia de Santa María, nos hace suponer que la antigua fábrica medieval ya habría sufrido por entonces importantes reformas, si no había sido derribada del todo. El cimborrio se elevaría sobre la cabecera, contribuyendo a dar mayor luminosidad a la capilla mayor; dicha estructura sostendría o bién una cúpula, o bien una cubierta abovedada. Constituye una solución muy innovadora, que encuentra en Compostela un único paralelo en la capilla del Hospital Real ${ }^{73}$. El cimborrio de Santa María sería demolido con toda probabilidad a mediados del siglo XVIII, momento en que se amplió y se rehizo la capilla mayor ${ }^{74}$.

Los dos arcos de medio punto sencillos y lisos, que actualmente dan entrada a la capilla funeraria de los Neira de Luaces, también deben ser producto de la misma reforma del XVIII, ya que en nada se parecen al arco que trazó Moreiras que -tal como se dice en el contrato susodicho- era de piedra de granito labrada y escodada por dentro, con un relive y "salisa" por fuera. Las obras de ampliación ochocentistas debieron implicar el derribo del muro en que se abría ese arco.

72 GOY DIZ, Ana, A actividade, vol. 1, docs. 424, pp. 278.

73 El cimborrio de la capilla del Hospital Real se cubrió con bóveda pétrea, que es obra de la tercera década del siglo XVI y que responde a un nuevo planteamiento de la escuela salmantina acorde con la sensibilidad renacentista asimimilada en lo ornamental; en un primer momento se encargó su ejecución a Jácome García (colaborador de Juan de Álava en el claustro de la catedral Compostelana ) "que tenia comenzada, la cual dicha bóveda", pero en 1527 se traspasa a los maestros Juan Pérez, Diego de los Prados y Juan de Villaverde, conviniendo que el compromiso afectaría tan solo al "casco de la dicha bóveda"; véase: VILA JATO, María Dolores, A Arte de Compostela. O Renacimiento. A Coruña, 1993, p. 69. VILA JATO, María Dolores, "Galicia na época do Renacemento". Galicia Arte, tomo 12. Francisco Rodríguez Iglesias (Dir.). A Coruña, 1995, p. 29. ROSENDE VALDÉS, Andrés, El Grande y Real Hospital de Santiago de Compostela. Santiago de Compostela, 1999, p. 37.

74 En 1751 el mayordomo de la parroquia de Santa María do Camiño señaló que el 8 de enero de 1747 " [...] se avía tratado de demoler y fabricar de nuevo la Capilla maior de la refida iglesia, ensánchandola más de lo que hera, dándole facultad como tal fabriquero [...] para ajustar la obra y objetar lo más conduzente [...]" y en el Cabildo general del 23 de junio de 1749, se acordó que estando la obra próxima a su terminación y a falta de retablo, era preciso conseguir el dinero necesario; en: GARCÍA-ALCAÑIZ YUSTE, Julia, Arquitectura, p. 189 y COUSELO BOUZAS, José, Galicia artística, pp. 416 y 427, notas al pie. 


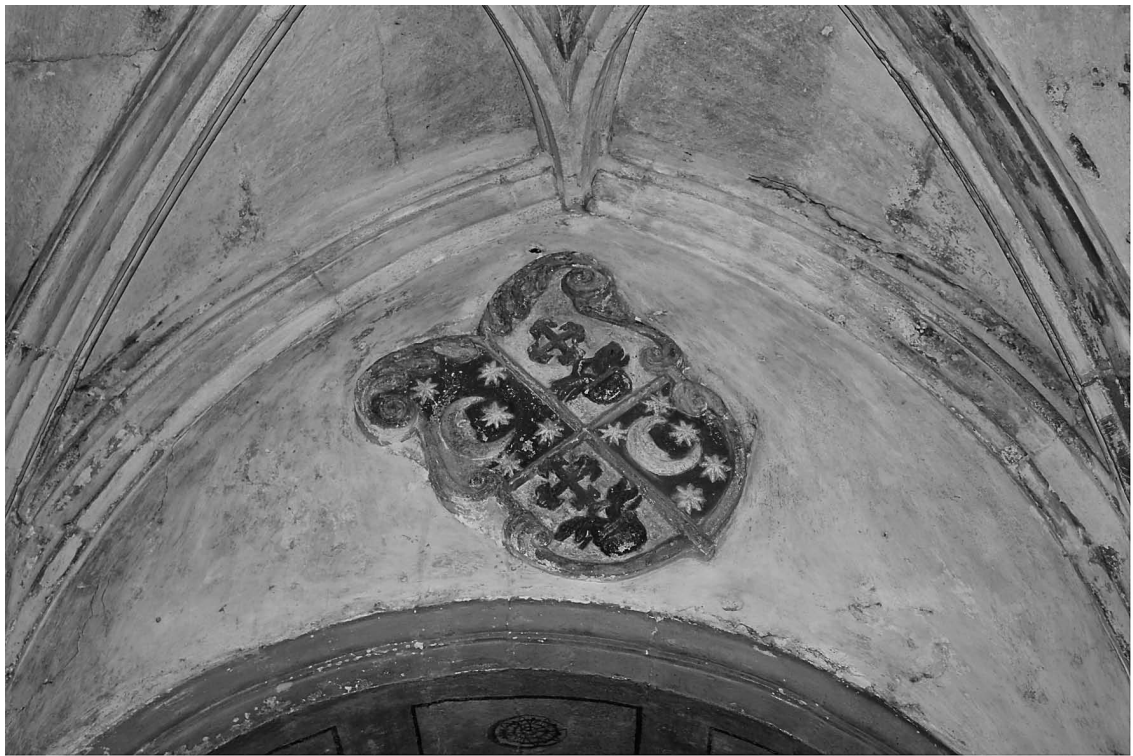

Fig. 9

Escudo sobre el arcosolio del lado occidental de la capilla

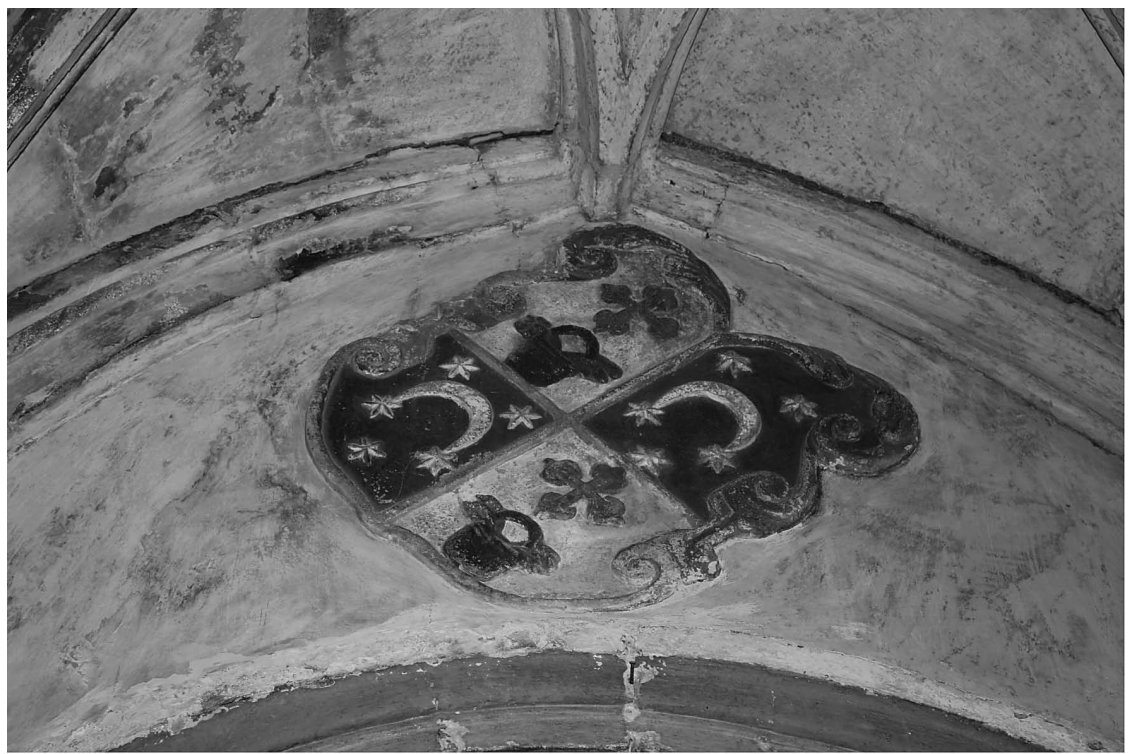

Fig. 10

Escudo sobre el arcosolio del lado oriental de la capilla 
En el muro norte de la capilla funeraria se abren dos arcosolios de desiguales dimensiones, se ubican uno por cada tramo del recinto y tienen arcos de medio punto que están descentrados con respecto a los arcos formeros de las bóvedas, con las que nada tienen que ver desde un punto de vista estilístico. Ambos arcos ornan el intradós con pinturas que simulan casetones. Sobre ellos figuran dos escudos en forma de cartela y dispuestos a la valona, uno de ellos contrapuesto por razón de cortesía, donde se recogen los emblemas propios y bien conocidos de los Neira y Luaces (figs. 9 y 10); las representaciones son en cuartelados igualmente contrapuestos, y presentan una ligera diferencia en cuanto a la disposición de las figuras alusivas a los Luaces. Nada cabe precisar en cuanto a la cronología de estas piezas, pues su factura podría corresponder a un amplio período, entre la segunda mitad del siglo XVI y principios del XVII ${ }^{75}$.

El nicho del arcosolio del lado de poniente está ocupado por una yacija sepulcral sobre la que se encuentra una estatua orante (figs. 11 y 12). La estatua está labrada en granito caleado y revela cierta preocupación realista que se expresa en el tratamiento detallado de la indumentaria, de los rizos del peinado y de la barba, pero sobre todo en la caracterización del rostro y en la expresión solemne de la cara. La cabeza de la figura emerge de una amplia gorguera rizada que rodea por completo el cuello. La gorguera es circular, de borde ancho encañonado y cerrada, muy al uso de lo que se estilaba en tiempos de Felipe III, entre el último cuarto del siglo XVI y el primer cuarto del siglo XVII. En esa época, el empleo de la gorguera fue constante, puesto que los caballeros se las ponían incluso con las armaduras de corte como es el caso que nos ocupa. La figura viste coselete o media armadura, que como ya era habitual en la primera mitad del siglo XVII, se reduce a determinadas piezas del total que se componía con anterioridad; esto es, el caballero lleva peto y espaldar, guardabrazos que cubren parte de los pectorales y los hombros, los brazales con sus correspondientes codales, las rodilleras y los zapatos herrados. Sobre el coselete luce una banda cruzada -expresiva de un rango militar- y por debajo asoman las calzas enriquecidas mediante listones bordados. En la mano derecha que cae a un lado del cuerpo, porta un rosario. Apoya la otra mano sobre la rodilla izquierda, que está doblada sobre el suelo; a esa rodilla se arrima la empuñadura de la espada. La pierna derecha permanece hincada sobre un rico cojín rematado con cuatro borlas. Al lado del caballero, un escabel cubierto con holgado tapete sustenta las manoplas y el almete de vista entera, con burelete y plumas.

Por la similitud de su composición y estilo, algunos autores han establecido paralelismos entre esta escultura y la del caballero sanjuanista de la iglesia pa-

\footnotetext{
75 Como en el caso de la labra colocada sobre la clave de la bóveda -que hemos descrito anteriormente-, no hemos tenido en cuenta los esmaltes, pues se advierte igualmente que estos escudos también fueron repintados.
} 


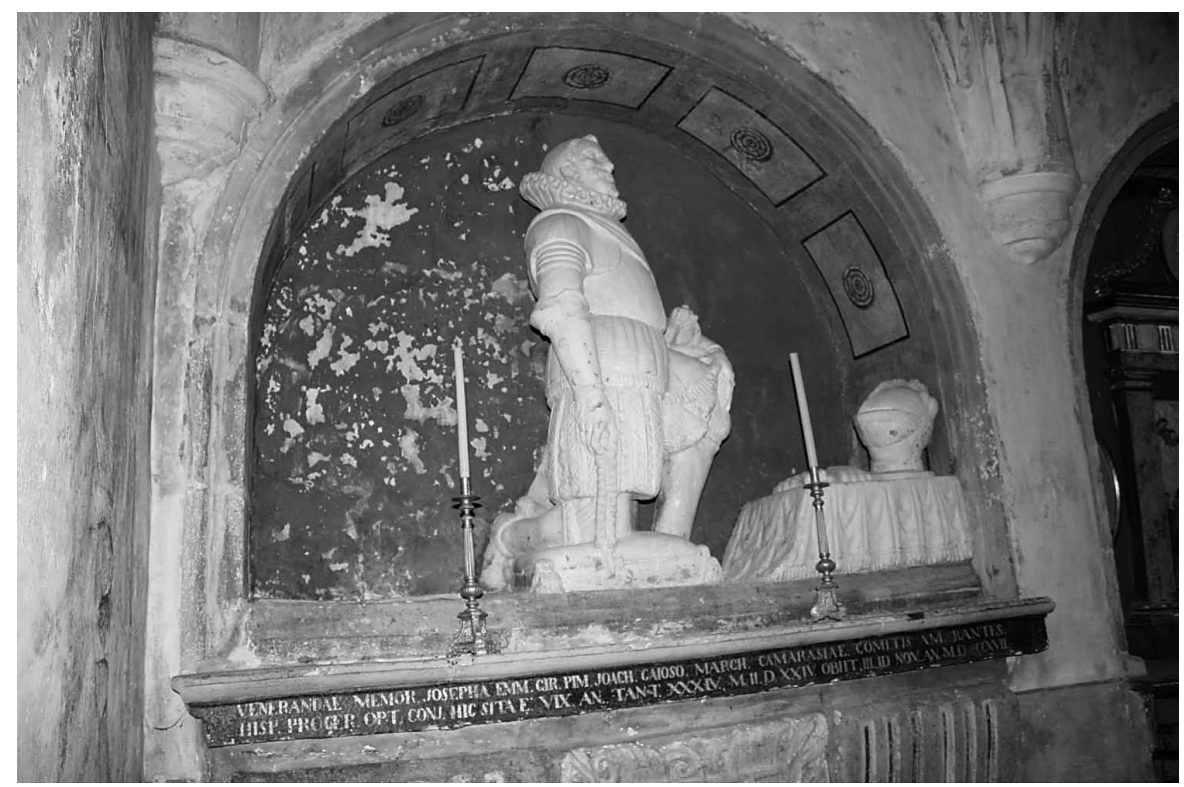

Fig. 11

Estatua orante de Gonzalo de Neira y Luaces Bermúdez de Castro (vista de perfil)

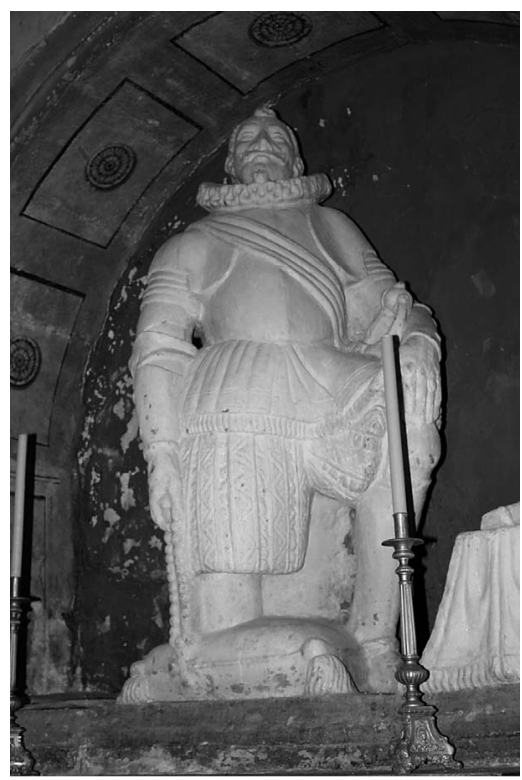

Fig. 12

Estatua orante de Gonzalo de Neira y Luaces Bermúdez de Castro (vista de frente) 
rroquial de Beade (Ourense), obra de Francisco de Moure, en el tránsito del manierismo al barroco, entre los siglos XVI y XVII ${ }^{76}$.

El personaje que representa la estatua orante de esta capilla de Santa María, pertenece -por su indumentaria castrense- al estamento militar; por esto y por la época en que puede inscribirse la escultura desde un punto de vista estilístico, dicho personaje podría ser Gonzálo de Neira y Luaces Bermúdez de Castro, hijo de don Juan de Luaces de Neira y de María de Mendoza y Bermúdez de Castro y nieto de Gonzálo el Mozo y María de Neira, quien a la muerte de su padre acaecida en el año 1608, heredó el señorío de Oca. Este personaje fue -como sus antecesores- regidor de Santiago y además ostentó el cargo de capitán de infantería. En 1606, participó con 1550 vasallos, en la guerra de Flandes. Casado con María de Pardiñas, señora de Vilardefrancos, murió el 5 de junio de 1648 sin descendencia, por lo que (como ya hemos visto más arriba) el señorío de Oca pasó a su hermana Catalina ${ }^{77}$.

Precisamente, el escudo con cartela y banderas acoladas, que actualmente está en el frontal del sepulcro (fig. 13), presenta en cuartelado las armas de los Luaces, Neira, Castro, Bermúdez y en el escusón, las de los Mendoza de la Vega, propias de la Casa del Infantado que los Menoza gallegos -de origen sevillano- tomaron

76 CHAMOSO LAMAS, Manuel, "La escultura funeraria en la iglesia de Santa María de Beade (Ribadavia-Orense)". Cuadernos de Estudios Gallegos, tomo 28 (1973), fasc. 86, p. 331. CHAMOSO LAMAS, Manuel, Escultura, pp. 112-113. GUTIÉRREZ PASTOR, Ismael, "Sobre Francisco de Moure y el Retablo de Santa María de Beade (Ourense): una estatua de Caballero de Malta semiarrodillado". El Museo de Pontevedra, vol. 47 (1993), pp. 129 y 132. OTERO TÚÑEZ, Ramón, "Santa María del Camino", pp. 111. La escultura de Beade está realizada en madera de nogal y según Gutiérrez Pastor, no se trata de una imagen funeraria, sino que formó parte del programa iconográfico que el escultor Francisco de Moure realizó para el retablo mayor de la iglesia, entre los años 1608 y 1613.

77 FERNÁNDEZ DE HENESTROSA Y ORTIZ DE MIOÑO, Ignacio, Apuntes, p. 243. BOUZABREY TRILLO, Fermín, "El origen”, pp. 233-234. CRESPO DEL POZO, José Santiago, Blasones, p. 11. LÓPEZ GÓMEZ, Pedro, "Historia del pazo", p. 152. Fernández Henestrosa identifica al orante con Gonzálo el Mozo, que nada tuvo que ver con el estamento militar. Por otra parte, no es posible que la escultura represente a Antonio de Beaufort, procesado en 1623 por la Inquisición, tal como dice Otero Pedrayo (seguido posteriormente por Carlos Casares), ya que este personaje nunca fue marqués de Camarasa, como asegura el autor y no pudo tener por ello, vinculación alguna con esta capilla de Santa María do Camiño. OTERO PEDRAYO, Ramón, Guía de Galicia. Vigo, 1965, p. 621 y CASARES, Carlos, Santiago de Compostela, patrimonio de la Humanidad. Madrid, 1988, p. 141; cit. en: OTERO TÚÑEZ, Ramón, "Santa María", p. 111. Por las fechas en que vivió Antonio de Beafort, era tercer marques de Camarasa Diego de los Cobos Guzmán y Luna (1612-1645). Como ya hemos dicho, la casa de Oca no llegó a entroncar con el marquesado de Camarasa hasta finales del siglo XVIII; anteriormente dicho marquesado, nada tenía que ver con la capilla de Santa María, por lo que dificilmente se podría identificar la figura orante de esta capilla con un márques de ese título, tal como dice Chamoso Lamas. CHAMOSO LAMAS, Manuel, Escultura, pp. 596-597. 


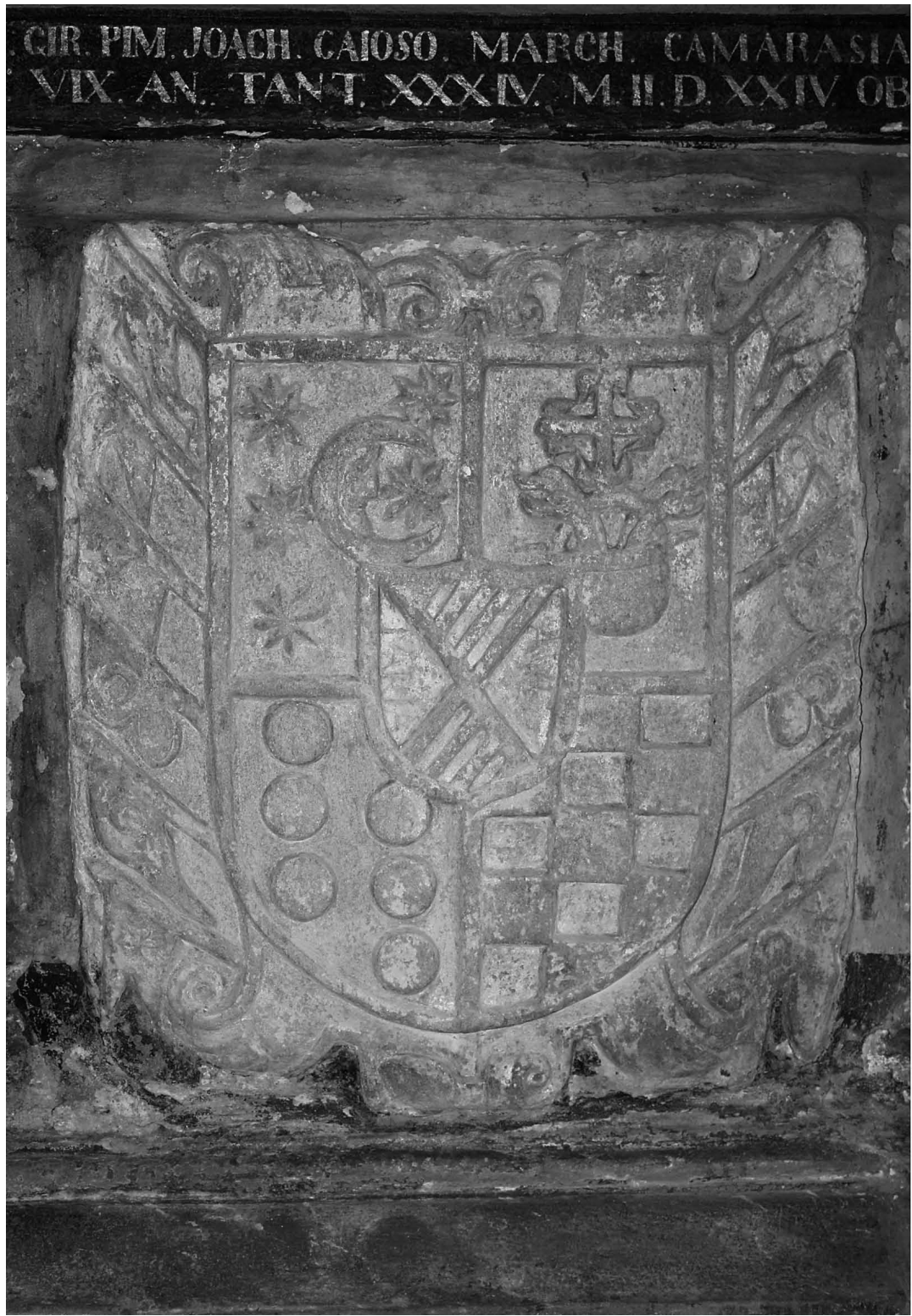

Fig. 13

Escudo con las armas de los Luaces, Neira, Castro, Bermúdez y Mendoza de la Vega 
modernamente como suyas ${ }^{78}$. El escudo, labrado en una sola pieza de granito enlucida con un color pardo amarillento, se encuentra encastrado entre otras dos piezas ornadas con una sucesión de bandas verticales -rebajadas en el interior- que estilísticamente nada tienen que ver con la piedra heráldica. Todo indica que el sepulcro fue abierto por el frente para poder efectuar más de una inhumación, conservándose en cualquier caso el escudo, al que posteriormente se le añadirían las piezas laterales, uniéndolas como están con mortero de hormigón.

En el canto de la cubierta de la yacija hay escrita una leyenda (fig. 14) con letras varias veces repintadas en dorado sobre fondo negro, que reza así:

VENERANDAE MEMOR.[IAE] JOSEPHA EMM.[ANUELA] GIR.[ON] PIM.[ENTEL] JOACH.[IM] GAIOSO MARCH.[IONIS] CAMARASIAE. COMITIS AM[A]RANTES. / HISP.[ANUS] PROCER. OP.T[IMUS] CONJ.[UX] HIC SITA E:[ST] VIX.[IT] AN.[NOS] TANT.[UM] XXXIV. M.[ENSES] II. D[IES] XXIV. OBIIT III ID[US] NOV.[EMBRIS] AN[NO] MD[C]CCXVII. ${ }^{79}$

Obviamente esta leyenda nada tiene que ver con la figura orante, ni con el escudo del frente de la yacija, si no con Josefa Manuela Téllez Girón Pimentel, marquesa de Marguini, nacida en Barcelona el 17 de agosto de 1783 y fallecida en Santiago el 11 de noviembre de 1817. Fue hija de los duques de Osuna y estuvo casada con Joaquín Gayoso de los Cobos y Bermúdez de Castro, XII marqués de Camarasa y último señor de Oca, nacido en 1778 y muerto en $1849^{80}$.

Para esta señora, uno de los más destacados escultores compostelanos del momento, Manuel Prado y Mariño (1773-1822), trazó el proyecto de un ambi-

\footnotetext{
${ }^{78}$ Un escudo con las mismas armas dispuestas de igual manera, se encuentra en la actualidad en el frente de la fachada de un caserón que da a la calle de "As Rodas" de la misma ciudad de Santiago, muy cerca de la iglesia de Santa María do Camiño; véase: ACUÑA RUBIO, Carlos, "Armas dos Luaces, Neira, Bermúdez, Castro e Mendoza, nu-n-ha casa da Rúa das Rodas (Santiago de Compostela)", Galicia. Heráldica, Xenealoxía e Nobiliaria, tomo 56. Francisco Rodríguez Iglesias (Ed.). A Coruña, (DL. 2008), pp. 40-41. Acuña Rubio, acierta al identificar tanto al orante, como el escudo de la yacija de la capilla de Santa María, con Gonzálo de de Neira y Luaces Bermúdez de Castro. Sin embargo se equivoca al señalar que en el frontal del sepulcro, una leyenda indica que ahí está enterrado el marqués de Camarasa, fallecido en 1617, que fue cuñado del citado Gonzalo de Neira. Sobre esta leyenda trataremos a continuación. ACUÑA RUBIO, Carlos, "Armas dos Luaces, Neira, Castro, Bermúdez e Mendoza no sepulcro do capitán don Gonzalo de Neira y Luaces Bermudez de Castro. Igrexa de Santa María do Camiño (Santiago de Compostela)" Galicia. Heráldica, Xenealoxía e Nobiliaria, tomo 56. Francisco Rodríguez Iglesias (Ed.). A Coruña, (DL. 2008), p. 299.

79 Aquí yace Josefa Manuela Girón Pimentel, de venerable memoria, esposa de Joaquín Gayoso, Marqués de Camarasa, Conde de Amarante, prócer óptimo hispano. Vivió tan solo 34 años, dos meses y veinticuatro días. Falleció tres dias antes de los idus de noviembre del año 1817.

${ }^{80}$ LÓPEZ GÓMEZ, Pedro "Historia del pazo", p. 157. EL ARCHIVO DUCAL DE MEDINACELI, en: http://www.fundacionmedinaceli.org
} 


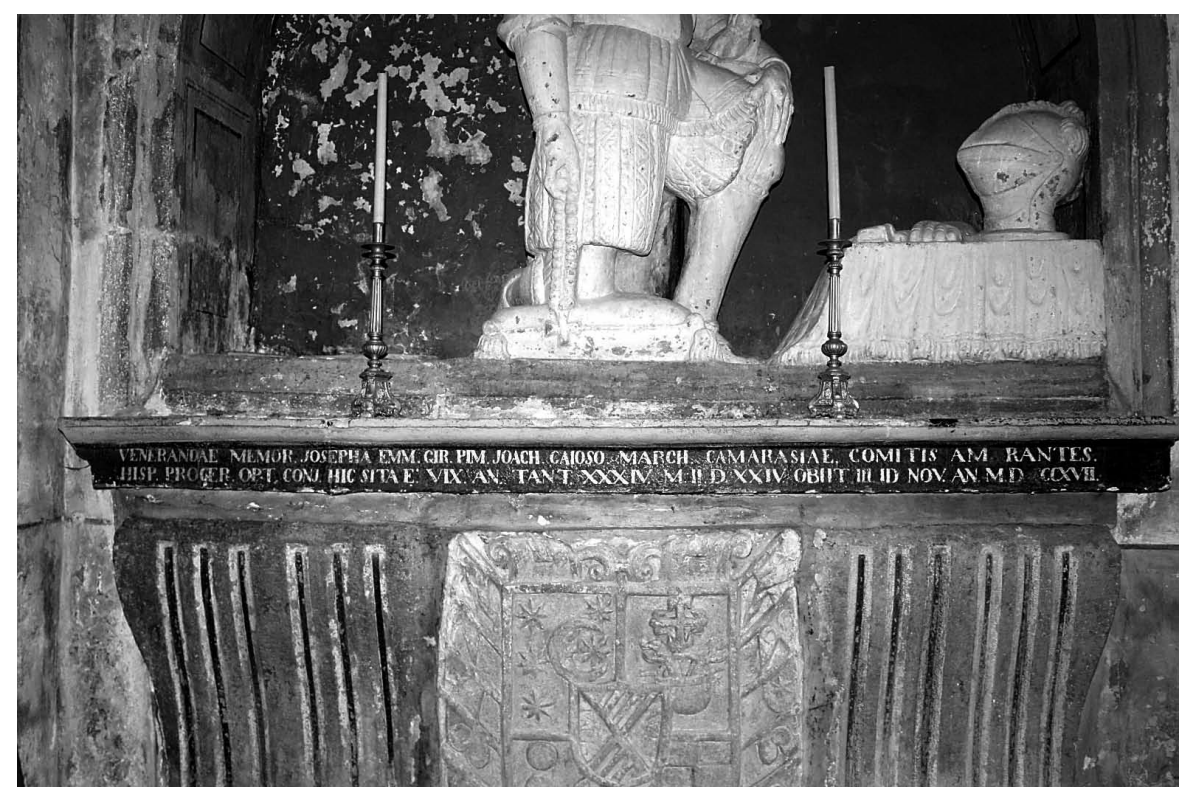

Fig. 14

Inscripción funeraria de Josefa Manuela Girón Pimentel

cioso mausoleo en la capilla mayor de Santa María do Camiño, que debería ser construido con mármoles traídos de Asturias; para llevar a cabo dicho proyecto, la capilla mayor tendría que ser reformada. El mausoleo nunca llegó a realizarse ${ }^{81}$. Poco después de haber sido abandonado el proyecto, muere Manuel Prado y la familia encarga para la capilla funeraria, un altar con su correspondiente retablo que se instaló aprovechando el nicho del arcosolio del lado Este. Se debió desmantelar en ese momento cualquier enterramiento que pudiera haber ahí.

El retablo encastrado en el hueco del arcosolio fue realizado en el primer tercio del siglo XIX por el académico de San Fernando, Antonio Sanjurjo, sucesor que fue de Manuel de Prado en los trabajos de imaginería efectuados para la iglesia de Santa María $^{82}$. El retablo de orden toscano enmarca la escena poco frecuente de la circuncisión de Jesús. A ambos lados se situaron dos medallones ovales con las representaciones en bajorelieve de los torsos de San Sebastián y San Roque, este

\footnotetext{
${ }^{81}$ Este escultor realizó la imagen de la Inmaculada que se encuentra en un altar lateral de la igesia de Santa María do Camiño; para la misma iglesia hizo las imágenes de la Virgen de la Aurora y de un Cristo para la cruz parroquial, que en la actualidad no se encuentran en las dependencias de Santa María. FILGUEIRA VALVERDE, José, Santiago, p. 109. LÓPEZ VÁZQUEZ, Xosé Manuel, "A Arquitectura Neoclásica", pp. 108-109. OTERO TÚÑEZ, Ramón, "Santa María del Camino", pp. 138-139.

${ }^{82}$ COUSELO BOUZAS, José, Galicia artística, p. 611.
} 
último -acompañado por el perro- aparece vestido de peregrino ${ }^{83}$; de estos óvalos dice Otero Túñez que "parecen obras de taller"84. En el ático del retablo, un medallón ensalzado entre sartas de laureles, enmarca el busto de un prócer representado de perfil al más puro estilo clasicista; el personaje es difícil de identificar, aunque no es descabellado pensar que pueda tratarse del propio marqués de Camarasa (fig. 15).

El lienzo de la pared del poniente de la capilla aparece ornado hoy en día, con pinturas muy del gusto decimonónico, que representan un dosel cuyo cortinaje arranca de una corona rodeada de haces de luz dorados. Estas pinturas constituyen la última intervención efectuada en la capilla funeraria, que adquirió por entonces la configuración defitiva con que ha llegado hasta nuestros días.

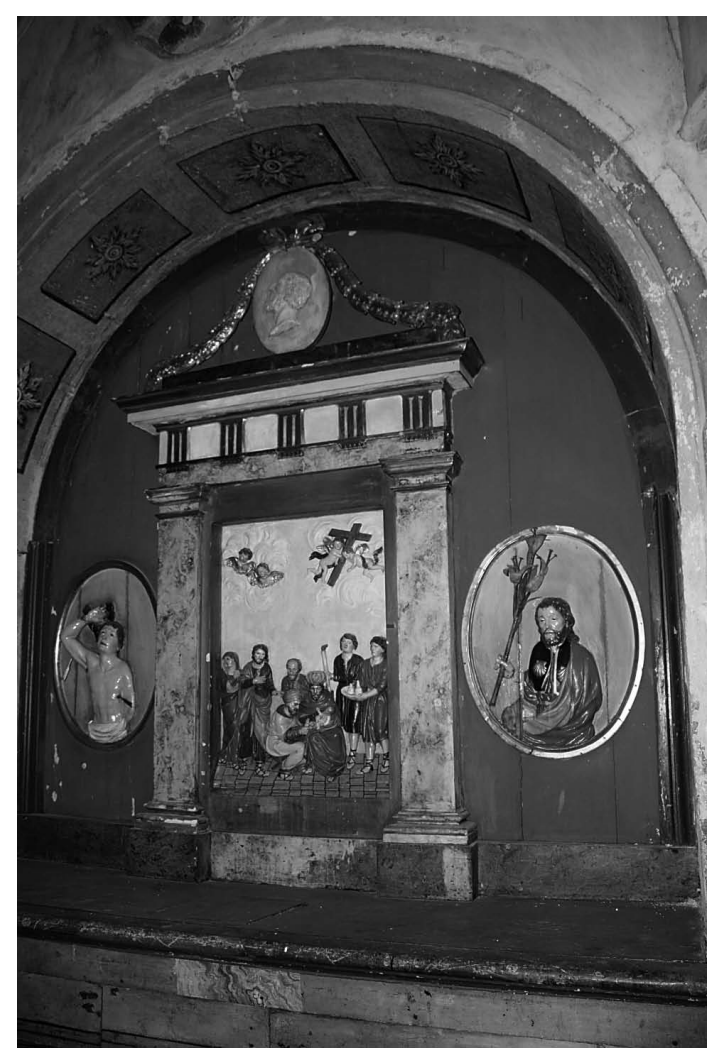

Fig. 15

Retablo decimonónico en la capilla de los Neira de Luaces

\footnotetext{
${ }^{83}$ La advocación a San Roque Peregrino está presente en todas las feligesías galaicas del Camino Fráncés y es con diferencia la más repetida.

84 OTERO TÚÑ̃E, Ramón, "Santa María del Camino”, pp. 140-141.
} 